ARTICLE

DOI: $10.1038 / \mathrm{s} 41467-018-03061-x$

\title{
A human endothelial cell-based recycling assay for screening of FcRn targeted molecules
}

\author{
Algirdas Grevys ${ }^{1,2}$, Jeannette Nilsen ${ }^{2,3}$, Kine M.K. Sand ${ }^{1,2}$, Muluneh B. Daba ${ }^{1,2}$, Inger Øynebråten ${ }^{4}$, Malin Bern ${ }^{1,2}$, \\ Martin B. McAdam 1,2, Stian Foss ${ }^{1,2}$, Tilman Schlothauer ${ }^{5}$, Terje E. Michaelsen ${ }^{6,7}$, Gregory J. Christianson ${ }^{8}$, \\ Derry C. Roopenian ${ }^{8}$, Richard S. Blumberg ${ }^{9}$, Inger Sandlie ${ }^{1,2} \&$ Jan Terje Andersen ${ }^{1,2,10}$
}

\begin{abstract}
Albumin and IgG have remarkably long serum half-lives due to $\mathrm{pH}$-dependent FcRn-mediated cellular recycling that rescues both ligands from intracellular degradation. Furthermore, increase in half-lives of IgG and albumin-based therapeutics has the potential to improve their efficacies, but there is a great need for robust methods for screening of relative FcRndependent recycling ability. Here, we report on a novel human endothelial cell-based recycling assay (HERA) that can be used for such pre-clinical screening. In HERA, rescue from degradation depends on FcRn, and engineered ligands are recycled in a manner that correlates with their half-lives in human FcRn transgenic mice. Thus, HERA is a novel cellular assay that can be used to predict how FcRn-binding proteins are rescued from intracellular degradation.
\end{abstract}

\footnotetext{
${ }^{1}$ Centre for Immune Regulation (CIR) and Department of Biosciences, University of Oslo, N-0316 Oslo, Norway. ${ }^{2}$ CIR and Department of Immunology, Rikshospitalet, Oslo University Hospital and University of Oslo, PO Box 4950, N-0424 Oslo, Norway. ${ }^{3}$ Institute of Clinical Medicine, University of Oslo, N0450 Oslo, Norway. ${ }^{4}$ Department of Pathology, Rikshospitalet, Oslo University Hospital and University of Oslo, N-0424 Oslo, Norway. ${ }^{5}$ Biochemical and Analytical Research, Large Molecule Research, Roche Pharma Research and Early Development (pRED), Roche Innovation Center, DE-82377 Munich, Germany. ${ }^{6}$ School of Pharmacy, University of Oslo, N-0371 Oslo, Norway. ${ }^{7}$ Norwegian Institute of Public Health, Infection Immunology, N-0403 Oslo, Norway. ${ }^{8}$ Jackson Laboratory, Bar Harbor, ME 04609, USA. ${ }^{9}$ Division of Gastroenterology, Department of Medicine, Brigham \& Women's Hospital, Harvard Medical School, 75 Francis St, Boston, MA 02115, USA. ${ }^{10}$ Department of Pharmacology, Institute of Clinical Medicine, University of Oslo and Oslo University Hospital, N-0424 Oslo, Norway. Jeannette Nilsen, Kine M. K. Sand and Muluneh B. Daba contributed equally to this work. Correspondence and requests for materials should be addressed to J.T.A. (email: j.t.andersen@medisin.uio.no)
} 
S ince the development of the hybridoma technology around 40 years ago $^{1}$, monoclonal antibodies have become important therapeutics, particularly for the treatment of cancer and autoimmune diseases ${ }^{2,3}$. Antibody engineering initially focused on humanization as well as improvement of antigen affinity ${ }^{4}$. There has been more recent interest in fine-tuning of the Fc region ${ }^{2,4}$. The major antibody class found in the blood, IgG, has a remarkable persistence, with a serum half-life of 20-23 days, compared with only hours or a few days for other circulating proteins ${ }^{5}$. The only exception is albumin, which has a similar long half-life, and is utilized as carrier for therapeutics ${ }^{6,7}$. In both cases, the long half-life is due to their molecular size above the renal clearance threshold and their interaction with a membranebound receptor named the neonatal Fc receptor (FcRn).

$\mathrm{FcRn}$ is an MHC class I-related molecule that consists of a transmembrane heavy chain (HC) that non-covalently associates with $\beta 2$-microglobulin ${ }^{8-10}$. The receptor binds both ligands noncompetitively in a strictly acidic pH-dependent manner, with negligible binding and release at neutral $\mathrm{pH}^{11-14}$. While FcRn binds the $\mathrm{CH} 2-\mathrm{CH} 3$ elbow region of IgG, both domain I and III of albumin are required for optimal binding to the receptor $^{13,15,16}$.

Advanced imaging studies have demonstrated that FcRn is predominantly located within acidified endosomes, where the low $\mathrm{pH}$ allows binding of IgG taken up by fluid-phase pinocytosis ${ }^{17}$. FcRn then recycles its IgG to the cell surface for release into the circulation upon exposure to the physiological $\mathrm{pH}$ of the blood ${ }^{18-}$ 20. Proteins that do not bind the receptor are directed to lysosomal degradation. As albumin binds $\mathrm{FcRn}$ in a similar $\mathrm{pH}$ dependent manner ${ }^{12,14,21,22}$, recent data support that it follows the same recycling pathway ${ }^{23}$. Further, FcRn expressed by endothelial cells regulate both ligands, hematopoietic cells determine IgG homoeostasis while hepatocytes regulate albumin but not $\operatorname{IgG}^{24-27}$.

Several studies have demonstrated the shortcomings of standard laboratory mice as pre-clinical models for evaluation of human IgG (hIgG) and human serum albumin (HSA) pharmacokinetics, due to considerable differences in binding kinetics towards mouse and human FcRn $(\mathrm{hFcRn})^{28-31}$. Specifically, hFcRn binds weakly to mouse IgG (mIgG), whereas mouse FcRn $(\mathrm{mFcRn})$ binds more strongly to hIgG than to $\mathrm{mIgG}^{28,29,31}$. The lack of binding of mIgG to hFcRn explains why murine antibodies are rapidly removed from the circulation in humans, despite long half-life in mice ${ }^{32}$. Injected recombinant IgG variants compete with endogenous ligands for FcRn binding, and the strong interaction between $\mathrm{mFcRn}$ and hIgG explains why the half-life of hIgG is longer than that of mIgG in WT mice $28,33,34$. Furthermore, both the mouse and human receptors bind more strongly to mouse serum albumin (MSA) than to HSA. Importantly, mFcRn binds HSA very poorly ${ }^{29}$, and consequently, HSA has a short half-life in WT mice 35,36 . Mice that are knock-out for $\mathrm{mFcRn}$ and transgenic for hFcRn have lower levels of $\mathrm{mIgG}$ and higher levels of MSA than what is found in WT mice ${ }^{21,37}$. Due to the high MSA levels, HSA also have short half-life in these mice ${ }^{35}$. Recently, hFcRn transgenic mice that lack MSA expression have been developed, and injected HSA shows considerably extended half-life of more than 20 days in these mice ${ }^{36}$.

Development of engineered IgG and albumin molecules with improved pharmacokinetics requires efficient screening procedures in which FcRn binding and cellular transport can be quantitatively closely monitored ${ }^{6,7}$. A major challenge in Fcengineering for improved pharmacokinetics is to increase the binding affinity for FcRn at acidic $\mathrm{pH}$ without a concomitant increase in affinity at near neutral $\mathrm{pH}$. This is crucial, as low affinity at near neutral $\mathrm{pH}$ is a prerequisite for efficient recycling and exocytosis, and one is faced with the same challenge when engineering the FcRn-albumin interaction. Furthermore, such engineering affects binding to the mouse and human receptors differently ${ }^{28,30}$, making it even more difficult to make reliable predictions. Except for advanced imaging analysis of molecular sorting and trafficking, no easy and robust in vitro cellular assay is available that allows predictions to be made on how well engineered IgG and albumin variants are rescued from intracellular degradation. Here, we report on a human endothelial cell-based recycling assay, abbreviated HERA, which is established to enable such screening of IgG and albumin variants, prior to evaluation in transgenic mice or non-human primates. Only small amounts of ligands are required, and there is no need for chemical labelling.

\section{Results}

HERA. We utilized a previously described human microvascular endothelial cell (HMEC1) line that grows as adherent monolayers. It is modified to stably express human $\beta 2$-microglobulin and the full-length hFcRn HC with an N-terminal HA-tag and EGFP-fused C-terminally (HMEC1-hFcRn) ${ }^{38}$. The expression of hFcRn was measured to be $>100$-fold higher than in the parental cell line (Supplementary Fig. 1a-c). We grew the HMEC1-hFcRn cells in wells until $95-100 \%$ confluency, removed the medium and incubated the cells for $1 \mathrm{~h}$ in HBSS buffer at $\mathrm{pH}$ 7.4. Subsequently, fresh buffer at $\mathrm{pH} 7.4$ or $\mathrm{pH} 6.0$ containing the proteins of interest were added, followed by incubation to allow for uptake. We found that an incubation step of $4 \mathrm{~h}$ was sufficient (Supplementary Fig. 2a). After washing, the cells were again incubated for $4 \mathrm{~h}$ with buffer at $\mathrm{pH} 7.4$ to allow for ligand release (Supplementary Fig. 2b). The amount of ligand that was taken up after the first $4 \mathrm{~h}$ incubation and the ligand recycled after additional $4 \mathrm{~h}$ was quantified by enzyme-linked immunosorbent assay (ELISA). In addition, we quantified the amounts remaining inside the cells after the recycling step by running ELISA on cell lysates. An illustration of the HERA principle is given in Fig. 1.

To address the effect of extracellular $\mathrm{pH}$ on rescue, titrated amounts of IgG were given at either $\mathrm{pH} 7.4$ or $\mathrm{pH} 6.0$ followed by washing and additional $4 \mathrm{~h}$ incubation at $\mathrm{pH}$ 7.4. The antibody used was a chimeric hIgG1 with mouse lambda light chain, hIgG1 constant $\mathrm{HC}$, and a $\mathrm{VH}$ providing specificity for the hapten 4 -
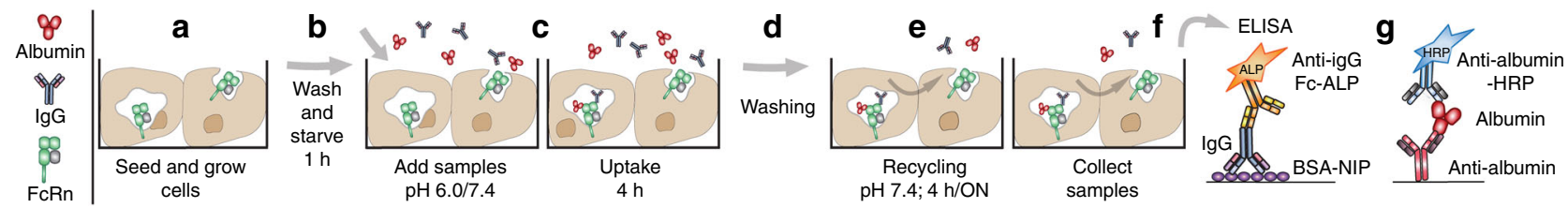

Fig. 1 The HERA protocol. a HMEC1-hFcRn cells are seeded and grown until confluent. b Cells are washed and starved for $1 \mathrm{~h}$ using HBSS (pH 7.4). c The protein of interest is diluted in HBSS ( $\mathrm{pH} 7.4$ or 6.0 ) and added to cells and incubated for $4 \mathrm{~h}$. $\mathbf{d}$ Medium is removed and cells are extensively washed with ice cold HBSS ( $\mathrm{pH} \mathrm{7.4)} \mathrm{before} \mathrm{the} \mathrm{cells} \mathrm{are} \mathrm{lysed} \mathrm{or} \mathrm{e} \mathrm{pre-heated} \mathrm{HBSS} \mathrm{(for} 4 \mathrm{~h}$ incubation) or growth medium (for overnight incubation (ON)) is added, incubated and samples collected. $\mathbf{f}$ Cells are extensively washed with ice cold HBSS ( $\mathrm{pH}$ 7.4) and lysed. $\mathbf{g}$ The collected samples are analysed in ELISAs specific for lgG or albumin 

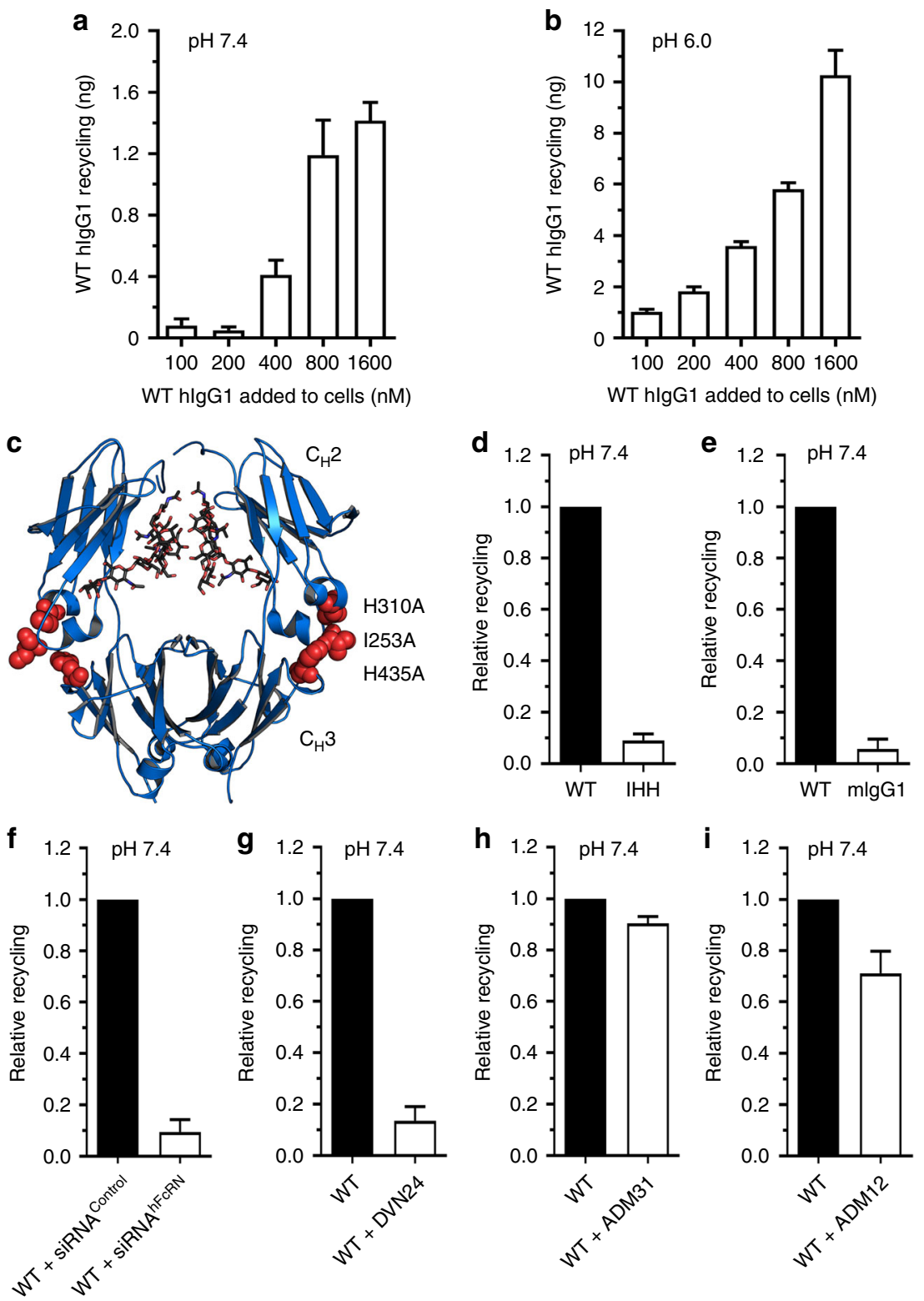

Fig. 2 Recycling of IgG is dependent on FcRn. Recycling of WT hlgG1 at a pH 7.4 and $\mathbf{b}$ pH 6.0 after $4 \mathrm{~h}$ incubation with titrated antibody concentrations (100-1600 nM). c An illustration of the hlgG1 Fc crystal structure where the mutated residues in hlgG1-IHH (I253A, H310A and H435A) are highlighted in red. The figure was designed by using the PyMOL software with the crystallographic data of hlgG1 $\mathrm{Fc}^{69}$. The amount (ng) recycled for each of the hlgG1 variants was used to calculate relative recycling compared with the WT that was set to 1.0. Histograms showing relative recycling of $\mathbf{d}$ WT and hlgG1-IHH, e WT hlgG1 and mlgG1, and $\mathbf{f}$ WT hlgG1 by HMEC1-FcRn cells transfected with control or hFcRn-specific siRNAs. Relative recycling of WT hlgG1 in the presence of $\mathbf{g}$ DVN24 (binds the IgG binding site on hFcRn), $\mathbf{h}$ ADM31 (binds the HSA binding site on hFcRn) and $\mathbf{i}$ ADM12 (does not bind the ligand binding sites) are shown. Obtained data are given as mean \pm s.d. of three independent experiments performed in duplicates

hydroxy-3-iodo-nitrophenylacetic acid (NIP). The amounts of anti-NIP antibody released from the cells were quantified, and at both $\mathrm{pH}$ conditions, concentration-dependent recycling was measured. However, roughly 10-fold more WT hIgG1 was released when the initial incubation step was performed at $\mathrm{pH}$ 6.0 (Fig. 2a, b). Thus, acidification during the incubation step sensitizes the assay.

Next, we compared recycling of the WT antibody with that of a hIgG1 variant containing three amino acid residue substitutions in the $\mathrm{CH} 2$ and $\mathrm{CH} 3$ domains of the $\mathrm{Fc}(\mathrm{I} 253 \mathrm{~A} / \mathrm{H} 310 \mathrm{~A} / \mathrm{H} 435 \mathrm{~A}$; hIgG1-IHH) (Fig. 2c), which eliminate IgG binding to $h F c n^{26}$. In addition, we included a recombinant anti-NIP WT mIgG1. When equal amounts of the antibodies were added to the cells at $\mathrm{pH}$ 7.4, both hIgG1-IHH and mIgG1 were found to be recycled poorly (Fig. 2d, e). This was as expected, as mIgGs bind only weakly to $\mathrm{hFcRn}{ }^{28,29,31}$. Further, we found that HMEC1-hFcRn cells treated with a mixture of siRNAs targeting the hFcRn HC gene downregulated the protein level by nearly $80 \%$ for up to $96 \mathrm{~h}$ (Supplementary Fig. 3a-b), which resulted in reduced recycling of WT hIgG1 by $90 \%$ compared with cells given control siRNA (Fig. 2f). Lastly, cells were incubated with WT hIgG1 in the presence of three monoclonal mouse antibodies raised against hFcRn, which block the binding site for IgG (DVN24), the binding site for albumin (ADM31), or the binding of neither ligand (ADM12 $)^{39,40}$. In the presence of DVN24, IgG recycling was abolished, while ADM31 did not interfere and ADM12 gave a minor reduction (Fig. 2g-i). Thus, recycling of hIgG1 was fully dependent on hFcRn. 
a $4 \mathrm{~h} \mathrm{pH} 6.0$ WT hlgG1
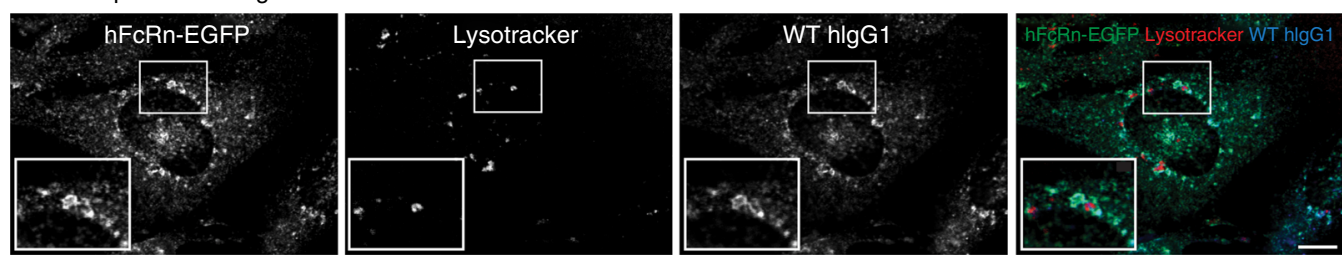

C $\quad 8 \mathrm{~h} \mathrm{pH} 7.4 \mathrm{WT}$ hlgG1
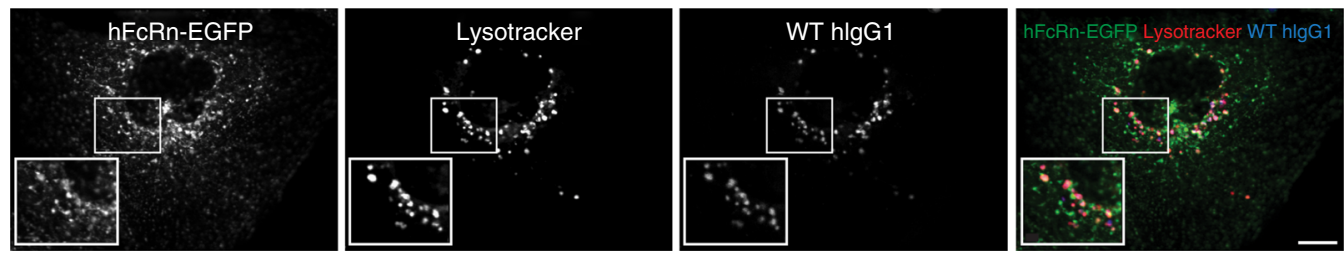

e $\quad 4 \mathrm{hpH} 6.0 \mathrm{hlgG} 1-\mathrm{HHH}$
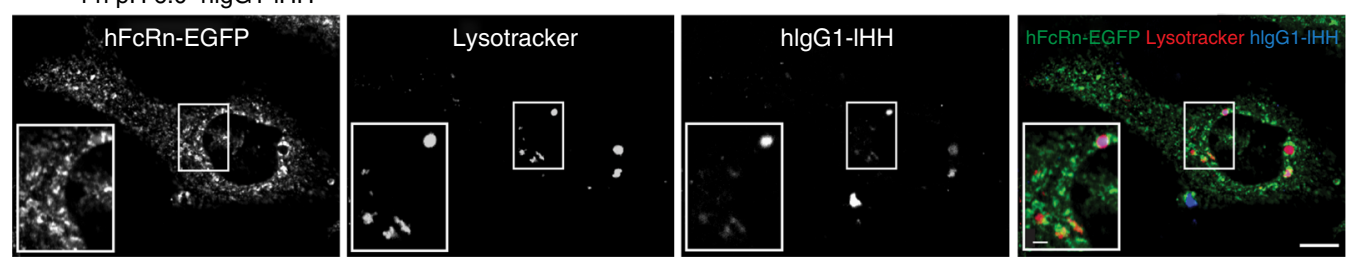

g

$8 \mathrm{~h} \mathrm{pH} 7.0$ hlgG1-IHH
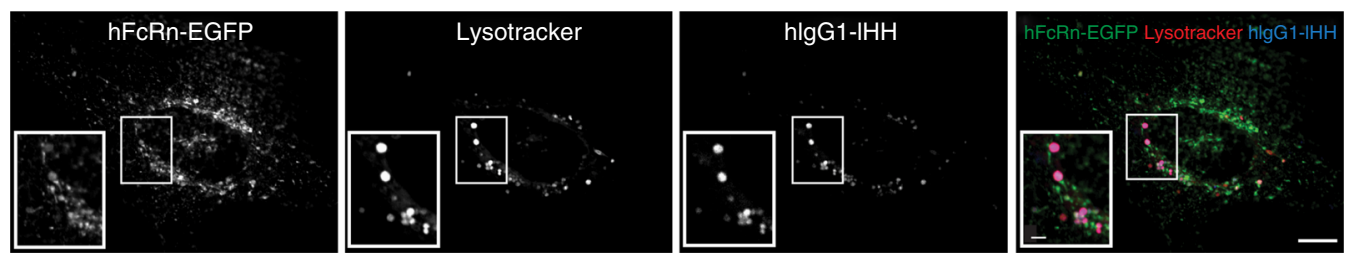

b
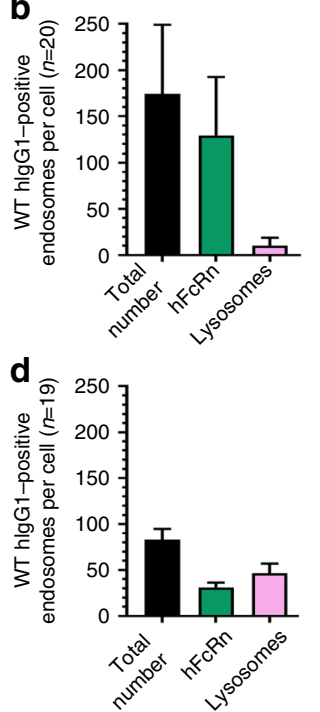

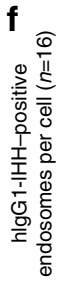
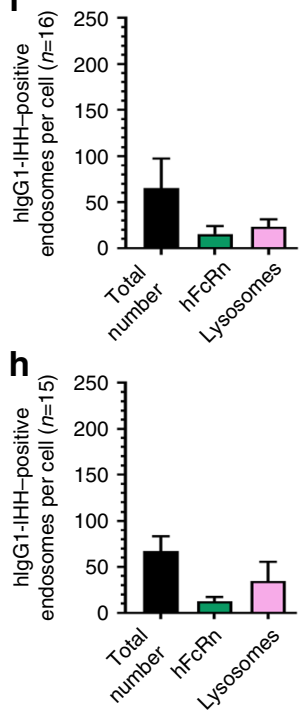

Fig. 3 Visualization of FcRn-mediated transport of IgG in HMEC1-hFcRn cells. HMEC1-hFcRn cells were seeded in eight-well Nunc ${ }^{T M}$ Lab-Tek $^{T M}$ chambered Coverglass imaging dishes, and live cell imaging was performed the day after. a Cells were washed three times with HBSS pH 6.0 and incubated with $400 \mathrm{nM}$ Alexa-labelled WT hlgG1 diluted in HBSS pH 6.0 for $4 \mathrm{~h}$ at $37^{\circ} \mathrm{C}$. Cells were incubated with Lysotracker DND-99 for 30 min before washed with HBSS pH 6.0 and images were taken. b WT hlgG1 co-localization with FcRn-positive endosomes or lysosomes after $4 \mathrm{~h}$ incubation ( $n=20$ cells). c The same cells as in a were washed three times with HBSS pH 7.4 followed by additional $4 \mathrm{~h}$ incubation at $37^{\circ} \mathrm{C}$ before images were taken. $\mathbf{d}$ WT hlgG1 colocalization with FcRn-positive endosomes or lysosomes after additional $4 \mathrm{~h}$ incubation $(n=19$ cells). e Cells were washed three times with HBSS pH 6.0 and incubated with $400 \mathrm{nM}$ Alexa-labelled hlgG1-IHH diluted in HBSS pH 6.0 for $4 \mathrm{~h}$ at $37^{\circ} \mathrm{C}$. Cells were incubated with Lysotracker DND-99 for 30 min and washed with HBSS pH 6.0 before images were taken. $\mathbf{f}$ hlgG1-IHH co-localization with FcRn-positive endosomes or lysosomes after $4 \mathrm{~h}$ incubation ( $n=$ 16 cells). $\mathbf{g}$ The same cells as in e were washed three times with HBSS pH 7.4 followed by additional $4 \mathrm{~h}$ incubation at $37^{\circ} \mathrm{C}$ before images were taken. $\mathbf{h}$ hlgG1-IHH co-localization with FcRn-positive endosomes or lysosomes after additional $4 \mathrm{~h}$ incubation ( $n=15$ cells). Representative confocal images at each condition are shown. Large scale bar-10 $\mu \mathrm{m}$; small scale bar-2 $\mu \mathrm{m}$. Co-localization analyses were performed using Imaris spot co-localization. Data are shown as mean \pm s.d. from two independent experiments were $n=20$ (b), 19 (d), 16 (f) and 15 (g) cells

Imaging of uptake and rescue of IgG. To visualize hIgG1 uptake and release as a function of $\mathrm{pH}$, we performed live cell confocal imaging of HMEC1-hFcRn cells. The cells were grown to $50-70 \%$ confluency before Alexa-647-conjugated WT hIgG1 or hIgG1-IHH was added at $\mathrm{pH} 6.0$ and incubated for $4 \mathrm{~h}$. Imaging revealed a high degree of co-localization of WT hIgG1 with the EGFP-fused receptor, suggesting that WT hIgG1 localized to recycling endosomes (Fig. 3a, b). After further incubation at $\mathrm{pH}$ 7.4, only low signals for the antibody were observed, suggesting that most of the antibodies had been released to the medium and a minor fraction sorted to the lysosomes (Fig. 3c, d). In contrast, we detected only minor co-localization of hFcRn-EGFP with Alexa-647-conjugated hIgG1-IHH at pH 6.0 whereas a larger fraction of the antibody was co-localized with a lysosomal marker (Fig. 3e, f). After buffer exchange to $\mathrm{pH}$ 7.4, even more hIgG1-IHH co-localized with the lysosomal marker (Fig. 3g, h). In addition, the set-up was repeated where both incubation steps were performed at neutral $\mathrm{pH}$ and the imaging results revealed that uptake of WT hIgG1 and hIgG1-IHH were similar at $\mathrm{pH} 7.4$ (Supplementary Fig. 4a-d). The major fraction of WT hIgG1 was shown to co-localize with FcRn-positive endosomes (Supplementary Fig. 4b) while most of hIgG1-IHH was localized to lysosomes (Supplementary Fig. 4d). 

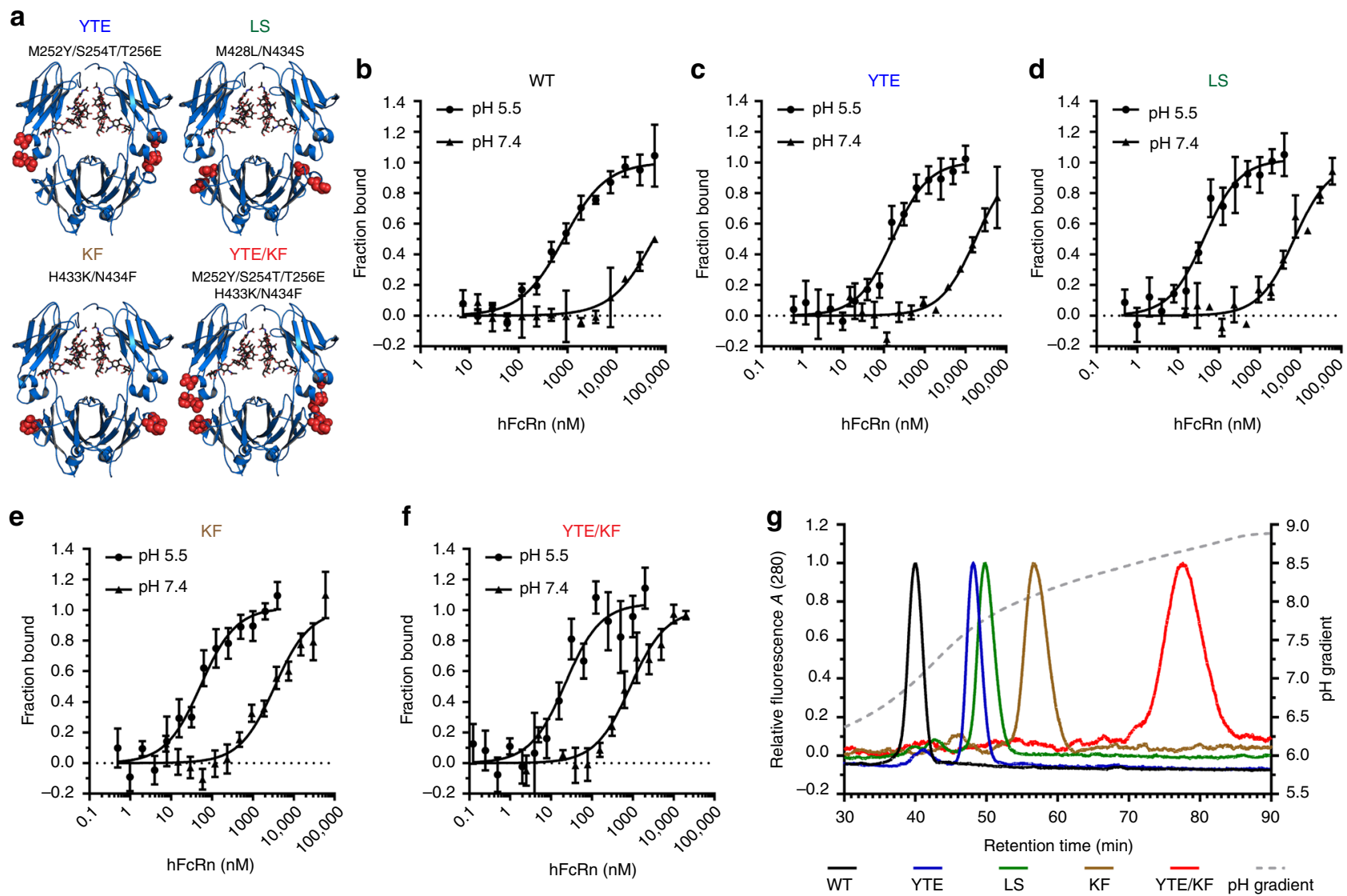

Fig. $4 \mathrm{hFcRn}$ binding characteristics of Fc-engineered IgG variants. a Illustrations of the crystal structure of hlgG1 Fc (blue) with the amino acid residues targeted by mutagenesis highlighted in red spheres: M252Y/S254T/T256E (YTE), M428L/N434S (LS), H433K/N434F (KF) and M252Y/S254T/T256E/ H433K/N434F) (YTE/KF). The figure was designed using the PyMOL software with the crystallographic data of hlgG1 Fc ${ }^{69}$. MicroScale Thermophoresis analysis where constant amounts (20 nM) of $\mathbf{b}$ WT hlgG1, c hlgG1-YTE, d hlgG1-LS, e hlgG1-KF and $\mathbf{f}$ hlgG1-YTE/KF were added to titrated amounts of $\mathrm{hFcRn}$ at pH 5.5 or 7.4. Binding data are derived from the specific change in the thermophoretic mobility and the ratio of normalized time-averaged (1 s) fluorescence intensities at defined time points of the MicroScale Thermophoresis traces $(-1$ and $5 \mathrm{~s})$. The data represent three independent experiments with three replicates; error bars show \pm s.d. between independent experiments. $\mathbf{g}$ Analytical hFcRn affinity chromatography of WT and Fc-engineered hlgG1 variants. The antibody elution profiles are shown as relative fluorescence intensity and as a function of a $\mathrm{pH}$ gradient

FcRn binding properties of Fc-engineered hIgG1 variants. Next, we compared WT hIgG1 with four previously described hIgG1 variants Fc engineered for altered FcRn-binding kinetics $^{28,41-43}$, all with NIP specificity ${ }^{44}$. Two of the antibodies have two substitutions in the CH3-domain, M428L/N434S (hIgG1-LS) and $\mathrm{H} 433 \mathrm{~K} / \mathrm{N} 434 \mathrm{~F}$ (hIgG1-KF), the third variant has three substitutions in $\mathrm{CH} 2, \mathrm{M} 252 \mathrm{Y} / \mathrm{S} 254 \mathrm{~T} / \mathrm{T} 256 \mathrm{E}$ and two in the CH3domain, H433K/N434F (hIgG1-YTE/KF), while the fourth has the three $\mathrm{CH} 2$ mutations only (hIgG1-YTE) (Fig. 4a). The binding affinities of purified antibody preparations were determined using MicroScale Thermophoresis at both $\mathrm{pH} 5.5$ and $\mathrm{pH}$ 7.4, by adding different concentrations of monomeric $\mathrm{hFcRn}$ to a constant amount of labelled hIgG1 variants (Fig. $4 \mathrm{~b}-\mathrm{f}$ ). The results obtained at $\mathrm{pH} 5.5$ revealed a hierarchy of FcRn binding relative to WT $(\mathrm{KD}=0.9 \mu \mathrm{M})$ as follows: YTE/KF bound 100 -fold more strongly, LS and KF showed similar binding affinities and bound 22- and 18-fold stronger, respectively, while YTE was the weakest binder with a 6-fold increase in affinity. At pH 7.4, the WT bound very weakly $(>60 \mu \mathrm{M})$ followed by 3 -fold stronger binding of YTE, while the LS and KF variants bound approximately 9-fold and 18-fold more strongly than the WT, whereas $\mathrm{YTE} / \mathrm{KF}$ again was the strongest binder with more than 75 -fold enhanced binding (Table 1).

FcRn-mediated recycling is a dynamic process that occurs through a $\mathrm{pH}$ gradient. To investigate how Fc-engineering affected dissociation from $\mathrm{hFcRn}$ as a function of $\mathrm{pH}$, we added the antibodies onto an hFcRn-coupled affinity column at $\mathrm{pH} 6.0$ and detected elution as the $\mathrm{pH}$ of the buffer was gradually increased towards pH 8.8 (Fig. 4g, Supplementary Table 1). The hIgG1 variants showed distinct profiles, where dissociation of the WT peaked at $\mathrm{pH}$ 7.0. YTE, LS and KF eluted with peaks in the $\mathrm{pH}$ range of 7.7-8.0. As expected, YTE/KF was released from the column at the highest $\mathrm{pH}$, at 8.5 . Thus, the Fc-engineered variants showed distinct $\mathrm{pH}$-dependent binding kinetics as well as $\mathrm{pH}$ elution profiles.

HERA screening of Fc-engineered hIgG1 variants. HERA was performed on the Fc-engineered hIgG1 variants as described above. We quantified the amounts of hIgG1 variants present inside the cells after $4 \mathrm{~h}$ incubation at $\mathrm{pH} 7.4$ and compared with WT. The results showed 5-fold more YTE and LS, 8-fold more KF and 13-fold more YTE/KF (Fig. 5a, d). Quantification of the amounts of antibody released from the cells after washing and the second $4 \mathrm{~h}$ incubation with fresh medium showed 6-fold more YTE and LS, 9-fold more KF and 13-fold more of the YTE/KF variant than WT (Fig. 5b, e). Quantification of the amounts that remained in the cells at termination of the assay revealed that 3fold more YTE and LS, 10-fold more KF and 50-fold more YTE/ $\mathrm{KF}$ accumulated compared to WT (Fig. 5c, f). The release step could also be run overnight without affecting the relative 
Table 1 KD values derived from MicroScale Thermophoresis analysis

\begin{tabular}{|c|c|c|c|c|}
\hline & $\begin{array}{l}K D \pm \text { s.d. }(n M) p H \\
5.5\end{array}$ & $\begin{array}{l}K D \pm \text { s.d. }(\mu M) p H \\
7.4\end{array}$ & $\begin{array}{l}\text { Fold difference compared } \\
\text { with WT pH } 5.5\end{array}$ & $\begin{array}{l}\text { Fold difference compared } \\
\text { with WT pH } 7.4\end{array}$ \\
\hline \multicolumn{5}{|c|}{ hlgG1 variants } \\
\hline WT & $964.3 \pm 128.0$ & $>60$ & & \\
\hline LS & $43.6 \pm 8.3$ & $7.0 \pm 2.0$ & 22.0 & $>9$ \\
\hline KF & $53.4 \pm 10.4$ & $3.3 \pm 0.9$ & 18.0 & $>18$ \\
\hline YTE/KF & $9.3 \pm 5.3$ & $0.8 \pm 0.2$ & 107.0 & $>75$ \\
\hline K573P & $49.6 \pm 8.5$ & $>70$ & 10.0 & NA \\
\hline
\end{tabular}

differences between the hIgG1 variants and WT (Supplementary Fig. 5a-c).

We then investigated how initial exposure of the antibodies to the cells at $\mathrm{pH} 6.0$ followed by washing and incubation at $\mathrm{pH} 7.4$ affected uptake, release and amount remaining inside the cells (Fig. $5 \mathrm{~g}-\mathrm{i}$ ). After the $4 \mathrm{~h}$ incubation at $\mathrm{pH} 6.0$, we detected 3 -fold more YTE and LS than that of WT inside the cells, as well as 3.5and 4-fold more KF and YTE/KF, respectively (Fig. 5g). Moreover, 4-5-fold more of all the variants, including YTE/KF, were detected in the medium compared to the WT (Fig. 5h). However, the amounts of the antibodies remaining inside the cells after additional $4 \mathrm{~h}$ incubation at $\mathrm{pH} 7.4$ were roughly the same as when all steps were performed at $\mathrm{pH} 7.4$ (Fig. $5 \mathrm{c}$, i). We also treated the cells with a mixture of siRNAs targeting the hFcRn $\mathrm{HC}$ to address whether the receptor was required for uptake, and found that it was not crucial for WT hIgG1, but that YTE/KF was less efficiently taken up when the receptor was downregulated (Supplementary Fig. 6a, b). Next, we calculated a so-called HERA score for each of the hIgG1 variants by dividing the relative difference in recycling (Fig. 5e) by the relative difference in residual amount (Fig. 5f). The estimations gave the highest score for YTE and LS while KF gave a similar score as the WT, and YTE/KF showed the lowest (Fig. 6a).

HERA score correlates with half-life values in hFcRn mice. To assess whether the HERA score could be used to predict the halflife of WT and the Fc-engineered hIgG1 variants, we measured the serum half-life in hFcRn transgenic mice after injection of equal amounts of antibody. The derived serum pharmacokinetic profiles showed that YTE and LS exhibited increased serum persistence compared with WT, resulting in half-life values of 12.6 and 11.2 vs 8.4 days, respectively (Fig. 6b, Table 2). Further, the KF variant was cleared somewhat faster than the WT with a half-life of 7.6 days while YTE/KF showed the shortest half-life (Fig. 6b, Table 2). Notably, none of the hIgG1 Fc-engineered variants showed increased serum persistence in WT mice (Fig. 6c). The HERA scores were then plotted toward the serum half-lives obtained in WT and hFcRn transgenic mice (Fig. 6d, e). We found a significant correlation with half-life in humanized mice ( $p$-values of 0.0014 ), but not in WT mice ( $p$-values of $0.2169)$. The remarkable differences in half-life of the hIgG1 Fcengineered variants between the mouse strains are reflected by their distinct binding properties for the mouse and human forms of the receptor, where $\mathrm{mFcRn}$ binds more strongly to the antibodies but less $\mathrm{pH}$ dependently (Supplementary Fig. $7 \mathrm{a}-\mathrm{d}$ ).

FcRn-mediated recycling of albumin in HERA. As FcRn does not only bind IgG, but also albumin, we adopted HERA to study recycling of WT HSA at different concentrations at either $\mathrm{pH} 7.4$ or 6.0. Release into the medium was quantified using ELISA, and at both $\mathrm{pH}$ conditions, concentration-dependent release was measured. Roughly three-fold more of HSA was detected in the medium when initial uptake was performed at pH 6.0 (Fig. 7a, b). Next, we tested how a mutant variant containing a single-point mutation in domain III (K500A) (Fig. 7c), which reduces binding to $\mathrm{hFcRn}$ by 30 -fold $^{14}$, and also MSA, which binds more strongly than HSA to $\mathrm{hFcRn}^{29,35}$, were recycled. MSA was recycled more efficiently than HSA, whereas the K500A mutant was poorly recycled compared with the WT (Fig. 7d, e). In addition, downregulation of the hFcRn HC expression levels with siRNA resulted in a reduction of almost 70\% (Fig. 7f), while addition of ADM31 reduced recycling of HSA by nearly $90 \%$ (Fig. $7 \mathrm{~g}$ ). Only a modest reduction was shown in the presence of DVN24 or ADM12 (Fig.7h, i).

Furthermore, we previously reported on an HSA variant with a single amino acid substitution in the C-terminal end of domain III (K573P) (Fig. 7c), which extended the serum half-life from 5.4 to 8.8 days in cynomolgus monkeys ${ }^{35}$. MicroScale Thermophoresis analysis revealed that K573P bound hFcRn 10-fold more strongly than WT at $\mathrm{pH} 5.5$ and only very weakly at $\mathrm{pH} 7.4(>70$ $\mu \mathrm{M}$ ), while WT had no detectable binding at $\mathrm{pH}$ 7.4 (Table 1, Fig. 7j, k). Analysis of the elution profiles on the hFcRn-coupled column showed that the WT and the K573P variant dissociated from the receptor at $\mathrm{pH} 6.4$ and 6.9, respectively (Fig. 7l, Supplementary Table 1). Thus, HSA dissociate earlier than that of WT hIgG1 (Fig. 4g, Supplementary Table 1). Using HERA, fourfold more K573P than WT was detected inside the cells after uptake, and also six-fold more was released during the recycling step (Fig. $7 \mathrm{~m}, \mathrm{n}$ ) as well as two-fold more remained inside the cells (Fig. 7o). The findings demonstrate that $\mathrm{hFcRn}$ expressed by endothelial cells rescues not only hIgG1, but also HSA from degradation and that engineering for enhanced FcRn binding translates into more efficient recycling and release.

FcRn transport of its two ligands. In vitro studies have shown that recombinant soluble FcRn binds IgG and albumin to separate binding sites in a non-cooperative manner ${ }^{12,16,21,22}$. However, whether the presence of one ligand interferes with binding and sorting of the other in a cellular context has not yet been addressed. Thus, we studied uptake and release of WT hIgG1 and HSA when excess amounts of the other ligand were added. Equal amounts of WT hIgG1 (anti-adenovirus 5 hexon capsid protein) or WT HSA were added in the presence of rituximab $(8 \mu \mathrm{M})$ or anti-NIP hIgG1-YTE/KF $(2 \mu \mathrm{M})$ (Fig. $8 \mathrm{a}-\mathrm{d})$. The results revealed that the presence of YTE/KF reduced recycling of WT hIgG1 by $50 \%$, while no reduction was detected when rituximab was added 

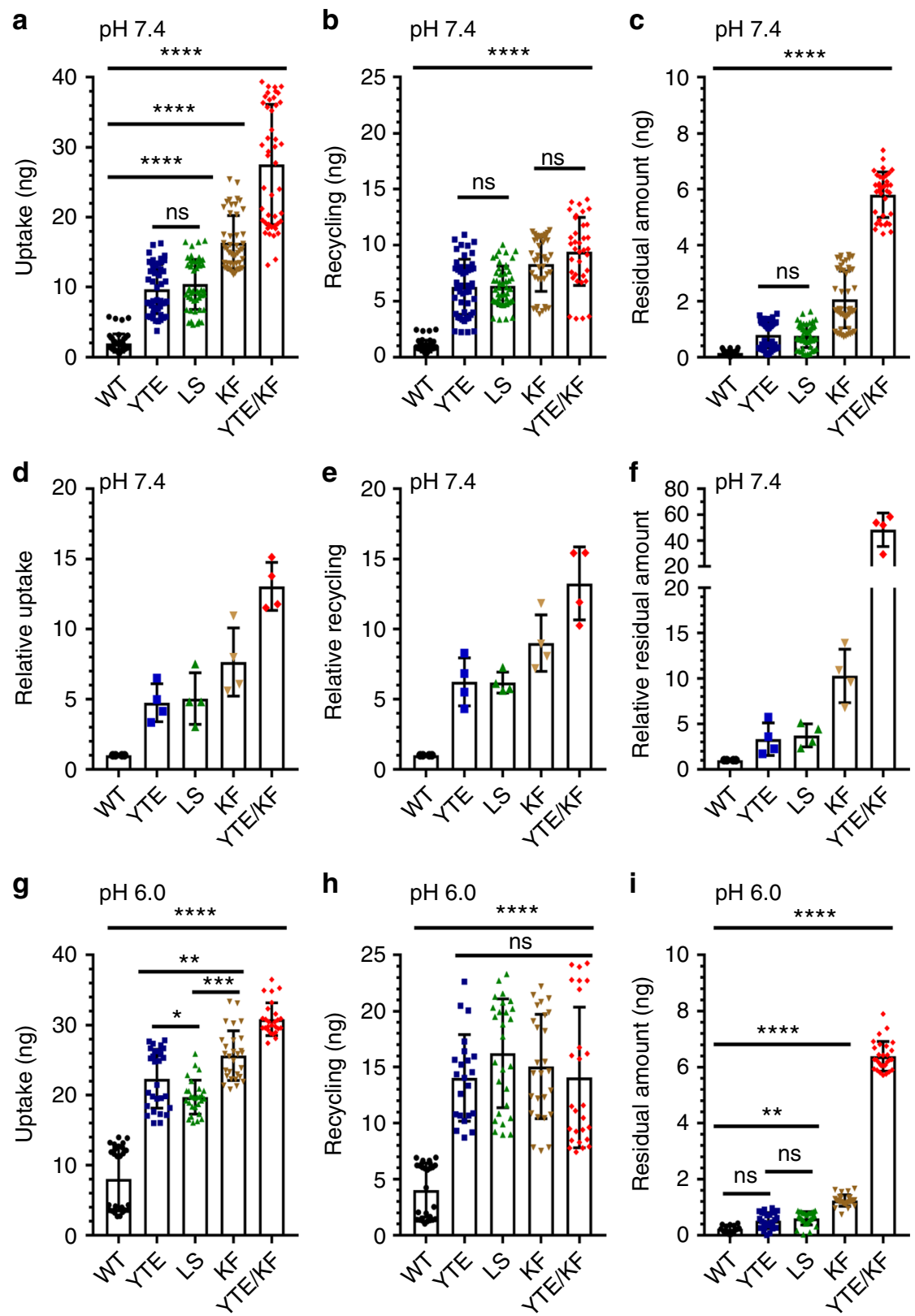

Fig. 5 HERA screening of WT and Fc-engineered hlgG1 variants. a Uptake of WT and Fc-engineered hlgG1 variants at pH 7.4 when $400 \mathrm{nM}$ of each variant was added to the cells followed by $4 \mathrm{~h}$ incubation, washing and lysis of the cells. $\mathbf{b}$ Recycling of the Fc-engineered hlgG1 variants at pH $7.4 \mathrm{when} 400 \mathrm{nM}$ of each variant was added to the cells and incubated for $4 \mathrm{~h}$ followed by extensive washing and additional $4 \mathrm{~h}$ incubation before sample collection. $\mathbf{c}$ The same procedure as in $\mathbf{b}$ followed by lysis of the cells. The amounts of hlgG variants in all samples were quantified by ELISA and obtained data are shown as mean \pm s.d. of four independent experiments performed in triplicates. ns $>0.05,{ }^{\star \star \star \star} p<0.0001$, by one-way ANOVA (Tukey's multiple comparison test). Relative $\mathbf{d}$ uptake, e recycling and $\mathbf{f}$ residual amount calculated from data (a-c), $\mathbf{g}$ uptake, $\mathbf{h}$ recycling and $\mathbf{i}$ residual amounts when WT and the Fcengineered hlgG1 variants were initially incubated at $\mathrm{pH}$ 6.0. The amounts of hlgG variants in all samples were quantified by ELISA, and obtained data are shown as mean \pm s.d. of two independent experiments performed in triplicates. ns $>0.05,{ }^{\star} p<0.05,{ }^{\star \star} p<0.01,{ }^{\star \star \star} p<0.001$ and ${ }^{\star \star \star \star} p<0.0001$, by oneway ANOVA (Tukey's multiple comparison test)

(Fig. 8b). Decreased levels were also detected for WT hIgG1 inside the cells, due to faster degradation expected in the absence of $\mathrm{hFcRn}$ available for binding (Fig. 8a), while uptake and rescue of HSA was unaffected except for a slight increase in rescue in the presence of an excess amount of rituximab (Fig. 8c, d).

Furthermore, we measured uptake and recycling of WT antiNIP hIgG1 in the presence of WT HSA $(8 \mu \mathrm{M})$ or an engineered HSA variant (E505Q/T527M/V547A/K573P; EQTMVAKP) (2 $\mu \mathrm{M})$ that binds $\mathrm{hFcRn}$ strongly and less $\mathrm{pH}$ dependently (Supplementary Fig. 8). While the engineered HSA variant did not affect uptake, the presence of WT HSA reduced uptake of hIgG1 by roughly $50 \%$ (Fig. 8e). Despite this, the amount of hIgG1 taken up was as efficiently recycled, as in the absence of WT HSA, while blocking of the albumin-binding site actually somewhat increased recycling of hIgG1 (Fig. 8f).

\section{Discussion}

Here we describe a cellular assay (HERA) that can be used for rapid screening of $\mathrm{hFcRn}$-dependent rescue from degradation of 

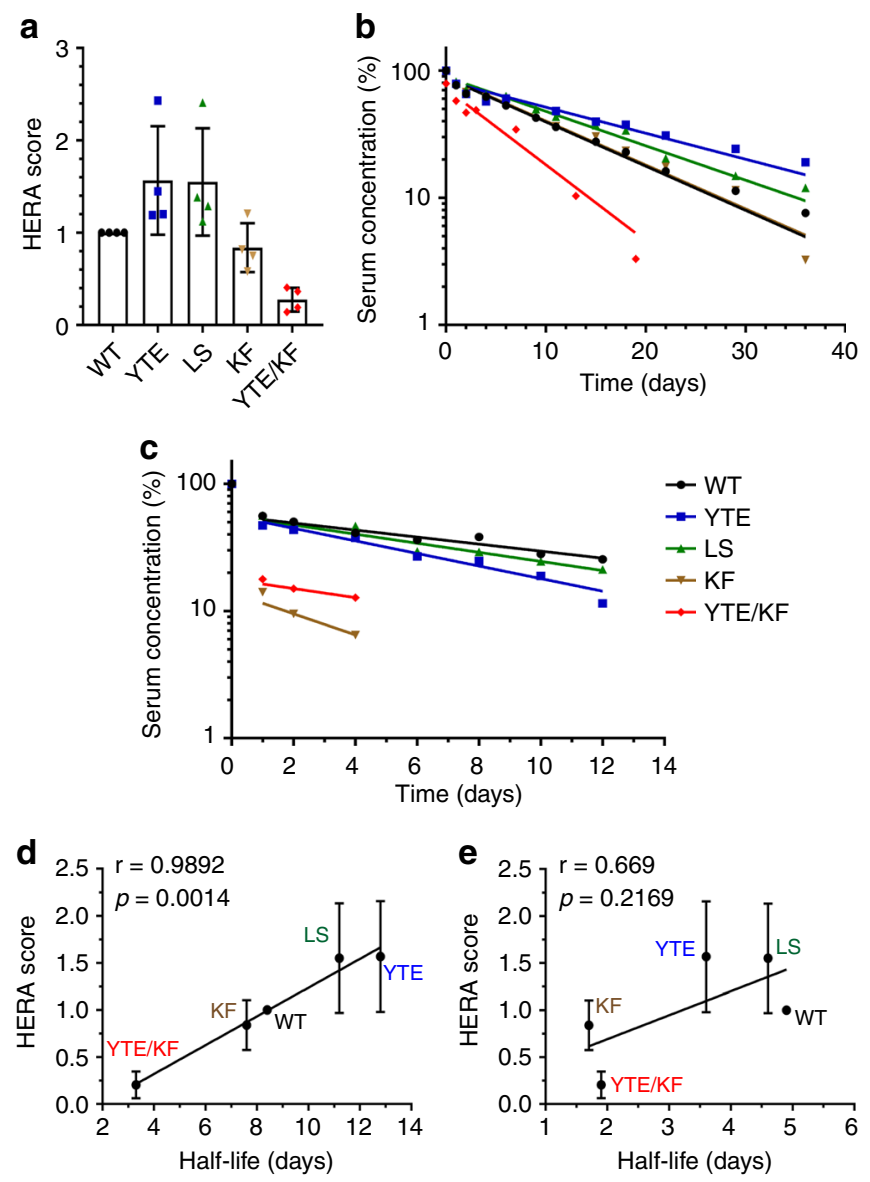

Fig. 6 HERA score correlates with in vivo serum half-life in hFcRn transgenic mice. a HERA score for the WT and the Fc-engineered hlgG1 variants were calculated from the data shown in Fig. 5e, f. b, c Log-linear changes in the serum concentration of hlgG1 WT (black), YTE (blue), LS (green), KF (brown) and YTE/KF (red) in hFcRn transgenic mice and WT mice, respectively. The antibodies were administrated as a single i.v. injection to 5 mice per group. Correlations of the derived HERA scores with serum half-life values of hlgG1 variants obtained from $\mathbf{d}$ hFcRn transgenic ( $r$ $=0.9892, p<0.0014)$ and e WT mice $(r=0.669, p<0.2169)$. The data are represented as mean \pm s.d.

engineered hIgG and HSA variants. We utilized the endothelial cell line HMEC1, which stably expresses $\mathrm{hFcRn}$ and can be grown as adherent monolayers, and uniquely regulates rescue of both IgG and albumin from degradation. The HMEC1-hFcRn cell line was chosen, as endothelial cells are known to be major sites for rescue of IgG and albumin from degradation in an FcRndependent manner ${ }^{24,45}$. In addition, the cell line has been used extensively to study intracellular FcRn-mediated trafficking of IgG using imaging technologies ${ }^{17,18,38,46}$. The cells were grown as confluent monolayers. FcRn ligands were added and incubated with the cells for $4 \mathrm{~h}$ before the medium was removed by washing. During this period, ligands entered the cells, and FcRn binding and recycling or degradation was initiated. However, we lysed cell samples at this time point and defined the amount of ligand found intracellularly as "uptake". In a parallel set-up, fresh medium was instead added to collect ligand that was recycled and released during the subsequent $4 \mathrm{~h}$ incubation, defined as "recycling". At this time, these cells were also lysed and the amount of ligand found intracellularly was defined as "residual amount". To normalize the assay, we present the obtained values as relative to that found for the WT ligand. We observed that the recycled and residual amounts did not equal the amount taken up. This is likely due to degradation, a notion that is also supported by live imaging showing a fraction of IgG in the lysosomes at the end of experiments.

We used the assay to characterize and compare a panel of hIgG1 variants, with the same framework and specificity for NIP. All contained well-characterized $\mathrm{Fc}$ mutations that have been reported to improve $\mathrm{FcRn}$ binding and give rise to extended halflife in mice, non-human primates and humans $s^{28,41-43,47}$. In addition, we included a so-called Abdeg molecule (antibody that enhances degradation) that is engineered to bind more strongly in the $\mathrm{pH}$ range of $6.0-7.4^{41,48}$. The IgG variants were added to the medium at $\mathrm{pH} 6.0$ or 7.4. While considerably more of YTE, LS and $\mathrm{KF}$ were taken up and detected in the medium after recycling compared with the WT, no major differences were detected between these Fc-engineered variants. In contrast, cellular accumulation measured as residual amount varied in that more KF was found inside the cells. This corresponds well with the fact that $\mathrm{KF}$ binds more strongly to $\mathrm{FcRn}$ at $\mathrm{pH} 7.4$ and has a longer retention time on the FcRn column. Comparing LS and YTE, LS bound $\mathrm{hFcRn}$ almost four times more strongly than YTE at $\mathrm{pH}$ 5.5. However, it was not found in higher amounts inside the cells at the start of the recycling step, nor was it more efficiently recycled. This could be explained by stronger receptor binding at neutral $\mathrm{pH}$, but the difference in retention time between the variants on the $\mathrm{hFcRn}$-coupled column is minor.

Furthermore, we determined the half-life of the panel of antiNIP hIgG1 variants in WT and hFcRn transgenic mice and measured profound differences in the two strains, which mirror their distinct binding properties toward the mouse and human forms of $\mathrm{FcRn}^{28-31}$. Again, this highlights the importance of considering cross-species differences when measuring pharmacokinetics. Importantly, the calculated HERA scores for the hIgG1 variants were shown to correlate with in vivo half-life in hFcRn transgenic mice, but not WT mice. The assay is fast and convenient and we find it extremely useful and also sensitive. Furthermore, we found that the sensitivity could be increased by doing the initial uptake step at $\mathrm{pH}$ 6.0.

FcRn is predominantly found to be expressed within endosomal compartments, while only a minor fraction is displayed at or near the cell surface at least in parenchymal cells ${ }^{18,19}$. The influence of $\mathrm{pH}$ on $\mathrm{FcRn}$-mediated uptake and trafficking of IgG in different types of cells is a matter of debate ${ }^{49,50}$. Due to negligible $\mathrm{FcRn}$ binding of IgG at neutral $\mathrm{pH}$, cellular uptake may solely be dependent on fluid-phase pinocytosis, but data also support active involvement of $\mathrm{FcRn}^{51}$. The $\mathrm{Fc}$-engineered variants with increased binding at $\mathrm{pH} 7.4$ may thus engage FcRn at the cell surface or in early endosomes more efficiently than the WT. Our findings show that more of the WT and Fc-engineered variants were detected inside the cells when incubation was done at $\mathrm{pH}$ 6.0. This may support the notion above, but incubation at acidic $\mathrm{pH}$ will also prevent release during exocytosis and as such promote accumulation inside the cells. This is also supported by imaging, where the WT and $\mathrm{IHH}$ variants were taken up in equal amounts when given to the cells at $\mathrm{pH}$ 7.4. More of the WT was taken up than IHH when the assay was performed at $\mathrm{pH}$ 6.0. In line with this, when cells were treated with siRNA targeting FcRn, we found that uptake of WT hIgG1 was not dependent on the receptor, while active FcRn-mediated uptake was measured for the YTE/KF mutant variant. As FcRn is expressed as a fusion with a C-terminal EGFP, HERA may be combined with imaging studies to gain further mechanistic insights into how FcRn binds and transports therapeutics.

We found the KF mutant to have a similar HERA score and half-life as WT hIgG1 in hFcRn transgenic mice. It bound hFcRn with $3.3 \mu \mathrm{M}$ affinity at neutral $\mathrm{pH}$, while LS, which was more efficiently rescued, bound $\mathrm{hFcRn}$ with an affinity of $7 \mu \mathrm{M}$ at this 
Table 2 Serum half-life data in WT and humanized FcRn mice

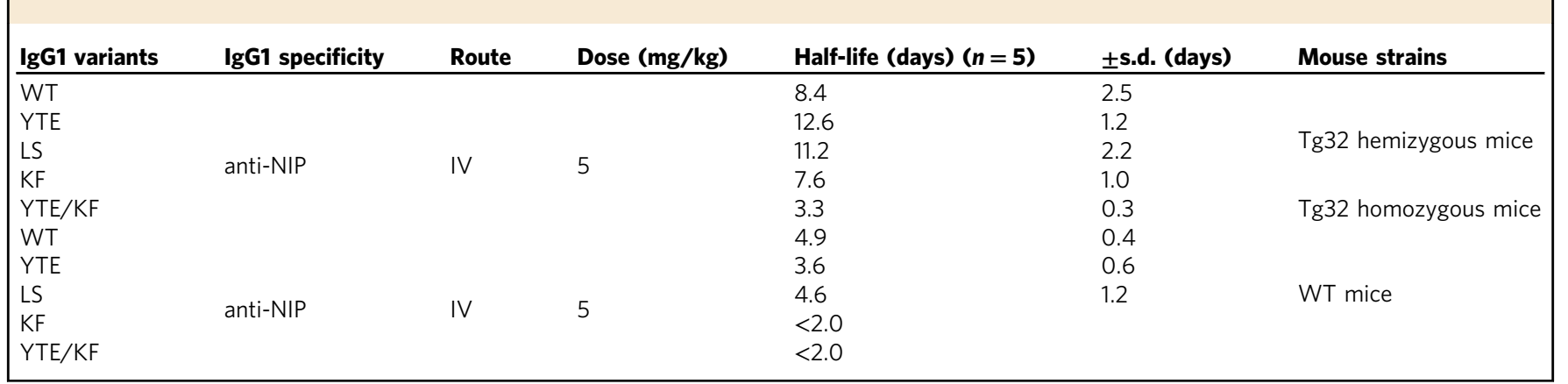

$\mathrm{pH}$. This means that the affinity threshold to achieve efficient recycling and release lies between $3-7 \mu \mathrm{M}$ as defined by MicroScale Thermophoresis. Notably, it has previously been shown that high affinity at acidic $\mathrm{pH}$ combined with binding affinity up to $0.8 \mu \mathrm{M}$ at neutral $\mathrm{pH}$, as defined by surface plasmon resonance measurements, resulted in extended half-life ${ }^{52}$.

While relative uptake and rescue of the three hIgG1 variants, YTE, LS and KF, were similar at the two $\mathrm{pH}$ conditions, this was not the case for YTE/KF, which was distinctly different regarding uptake, recycling and residual amount remaining inside the cells. The amount of YTE/KF recycled represented a minor fraction of the total pool of YTE/KF that was taken up and accumulated inside the cells, which is in accordance with live-imaging stu$\operatorname{dies}^{41,46}$. The distinct distribution of YTE/KF is mirrored by its $\mathrm{nM}$ affinity at $\mathrm{pH} 5.5$, more than 100-fold stronger than the WT, and sub- $\mu \mathrm{M}$ affinity at $\mathrm{pH} 7.4$, roughly 10 -fold weaker than at $\mathrm{pH}$ 5.5. Our study thus demonstrates that both the amounts recycled and remaining inside the cells should be measured to make a useful prediction of how $\mathrm{hFcRn}$-expressing cells will sort ligand variants in vivo. Thus, the residual amount of ligands was taken into consideration when calculating the HERA score, as well as the amount recycled.

We also adopted HERA to study HSA variants, and again, recycling was shown to depend on hFcRn, as only WT HSA and not a null binding mutant was rescued. Further, a HSA variant (K573P) engineered for improved $\mathrm{pH}$-dependent FcRn binding showed enhanced recycling and a HERA score of 2.5 , which mirrors its extended half-life in $\mathrm{hFcRn}$ transgenic mice and cynomolgus monkeys ${ }^{35}$.

Although it is well-established that both IgG and albumin bind FcRn in a similar $\mathrm{pH}$-dependent manner ${ }^{11-14}$, we found a distinct difference in dissociation as WT HSA was shown to elute earlier from the hFcRn column ( $\mathrm{pH}$ 6.5) than WT hIgG1 (pH 7.0). This finding may shed new light on how the two ligands are transported in different cell types through a $\mathrm{pH}$ gradient. With regard to engineering for enhanced rescue, it suggests that "the window for improvement" is wider for HSA than for IgG. Moreover, we showed that the ligands are transported by FcRn in the absence of the other, and the presence of rituximab did not negatively affect HSA rescue, but instead had a slightly enhancing effect.

Studies in mice have shown that the levels of endogenous IgG are considerably reduced in the presence of $\mathrm{YTE} / \mathrm{KF}^{41,46,48}$. We therefore used the YTE/KF variant to study transport of hIgG1 and HSA in HERA. In the presence of excess amounts of YTE/ $\mathrm{KF}$, where most of the IgG binding sites on $\mathrm{hFcRn}$ are expected to be occupied, reduced rescue of WT anti-hexon hIgG1 was observed, which was not observed in the presence of rituximab. In contrast, rescue of HSA was not affected. This pin points that HSA is still recycled and released when IgG is bound to the receptor, which is in line with data showing that YTE/KF is not affecting receptor trafficking, but instead hijacks the receptor throughout the endosomal pathway ${ }^{41,53}$. When hIgG1 was given in the presence of an engineered HSA variant that binds strongly and less $\mathrm{pH}$ dependently, the antibody was recycled somewhat more efficiently than in the presence of WT HSA. Notably, while uptake of hIgG1 was unaffected in the presence of the engineered albumin variant, the presence of WT HSA reduced uptake of the antibody. Whether this reflects biology or is an artefact due to the large amounts of WT HSA added needs to be further investigated.

In addition to the direct interaction between FcRn and its ligands, there are several additional factors that may contribute to define half-life, such as the expression level and availability of the target antigen, which may enhance clearance. Thus, HERA is expected to only correlate with half-life when the clearance mechanism is studied at dose levels dominated by FcRn binding and transport. However, HERA should be an attractive tool to study how the presence of soluble antigen is affecting cellular transport of the immune complex as well as how engineering for $\mathrm{pH}$-dependent antigen binding is affecting recycling and release of the ligand and antigen, respectively ${ }^{54,55}$.

Further, it was recently shown that the $\mathrm{pI}$ of IgG may influence cellular uptake ${ }^{55}$. In addition, the choice of framework can affect the pI, and thus the half-life ${ }^{56}$. It is also a matter of debate whether the Fab arms may influence FcRn binding. Support for this has been provided using hydrogen-deuterium exchange mass spectrometry, which indicated that there may either be a direct interaction or possibly a conformational link between the Fab arms and the constant Fc during complex formation with the receptor $^{57}$. A direct role of the Fab arms has been shown to depend on the charge of the Fv part, as IgGs with differences in charge have a great influence on $\mathrm{pH}$-dependent dissociation from an hFcRn-coupled column ${ }^{58}$ and receptor-binding kinetics ${ }^{59}$. The effect of such structural differences on uptake and FcRn-mediated sorting may be addressed using HERA. However, during early stage development, it is important to eliminate antibodies with off-target reactivity. This may be done using assays assessing binding to panels of non-cognate proteins ${ }^{60-62}$. Interestingly, it was recently shown that this may simply be done by screening the antibodies towards recombinant chaperone proteins that correlated with clearance in mice ${ }^{63}$. After such exclusion, HERA may be an attractive tool for screening and ranking not only monoclonal IgG antibodies and Fc-engineered variants, but also other formats such as anti-FcRn blocking reagents, Fc and albumin fusions as well as immunoconjugates prior to in vivo studies.

\section{Methods}

Cell culture. HEK293E cells (ATCC, Manassas, VA, USA) and the J558L murine myeloma cell line stably producing NIP-specific hIgG1-IHH were cultured in 


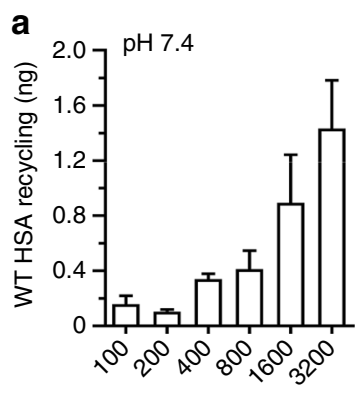

WT HSA added to cells (nM) b

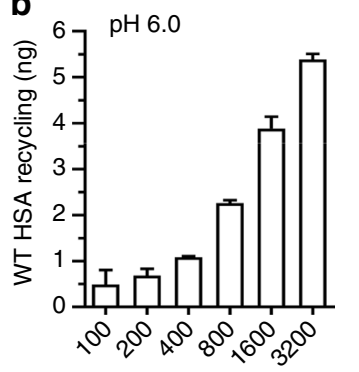

c

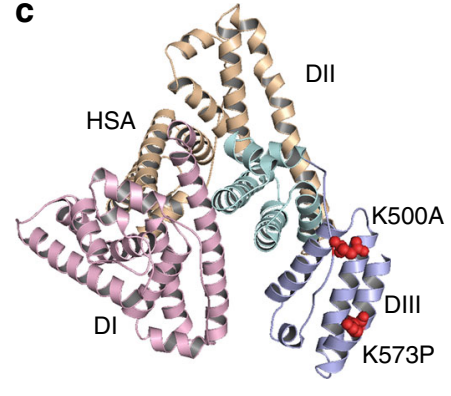

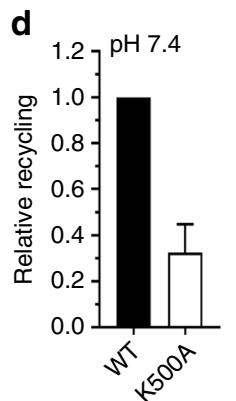

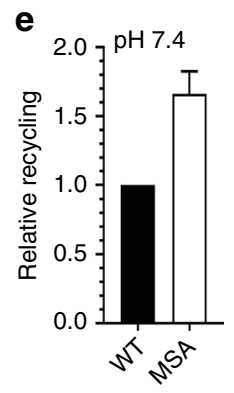

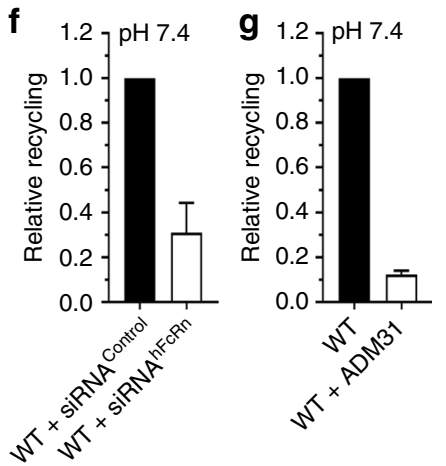

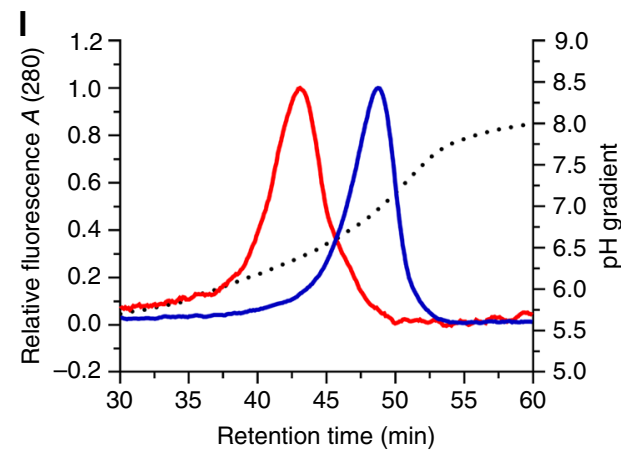

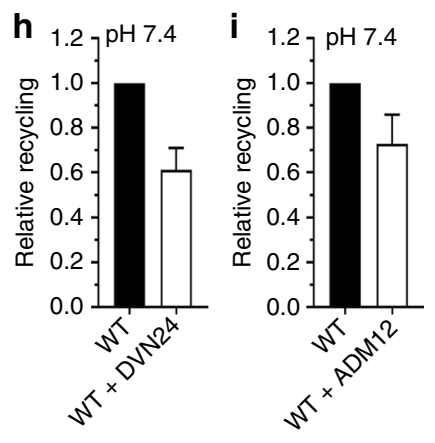

$s^{x}$
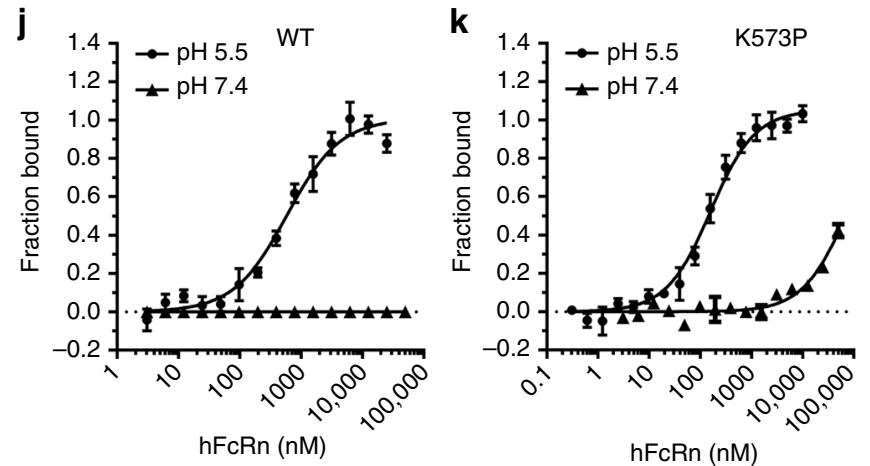
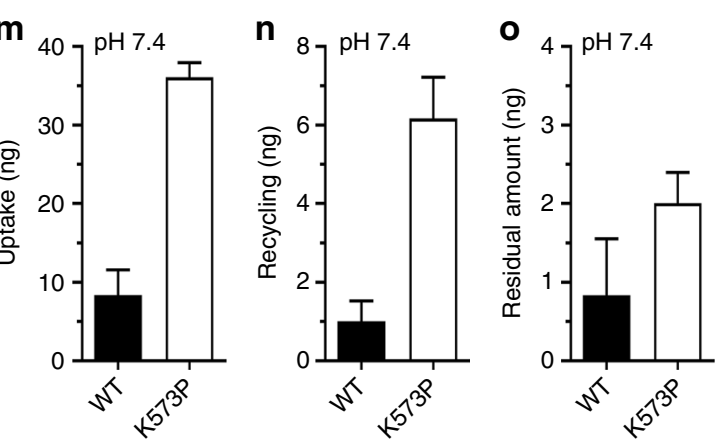

Fig. 7 HERA screening of HSA variants. Recycling of WT HSA at a pH 7.4 and $\mathbf{b}$ pH 6.0 after $4 \mathrm{~h}$ incubation with titrated HSA concentrations (100-3200 $\mathrm{nM}$ ). c An illustration of the crystal structure of HSA with the amino acid residues targeted by mutagenesis (K500A and K573P) highlighted in red spheres. The figure was designed using the PyMOL software with the crystallographic data of HSA ${ }^{70}$. Histograms showing relative recycling of $\mathbf{d}$ WT HSA and K500A, e HSA and MSA, f WT HSA by HMEC1-FcRn cells transfected with a control or hFcRn-specific siRNAs. Relative recycling of WT HSA in the absence or presence of either $\mathbf{g}$ ADM31 (binds the HSA binding site on hFcRn), $\mathbf{h}$ DVN24 (binds the lgG binding site on hFcRn) or $\mathbf{i}$ ADM12 (does not bind the ligand binding sites). MicroScale Thermophoresis measurements where $\mathbf{j}$ WT HSA-EGFP and $\mathbf{k}$ HSA-K573P-EGFP at a constant concentration (100 $\mathrm{nM}$ ) were added to titrated amounts of $\mathrm{hFcRn}$ at $\mathrm{pH} 5.5$ and 7.4. Binding data were derived from the specific change in thermophoretic mobility and the ratio of normalized time-averaged ( $1 \mathrm{~s})$ fluorescence intensities at defined time points of the MicroScale Thermophoresis traces $(-1$ and $4 \mathrm{~s})$. The data from three independent experiments with three replicates are shown where error bars show \pm s.d. I Analytical hFcRn affinity chromatography of WT and K573P. The elution profiles are shown as relative fluorescence intensity and as a function of a $\mathrm{pH}$ gradient. $\mathbf{m}$ Uptake, $\mathbf{n}$ recycling and $\mathbf{o}$ residual amounts when equal amounts of WT and K573P were added at pH 7.4. The amounts of HSA variants were quantified using ELISA. The obtained data are shown as mean \pm s.d. of two independent experiments performed in triplicates

RPMI 1640 (Sigma-Aldrich) supplemented with 10\% heat-inactivated fetal calf serum (FCS) (Sigma-Aldrich), $2 \mathrm{mM} \mathrm{L-glutamine,} 25 \mu \mathrm{g} / \mathrm{ml}$ streptomycin, and 25 $\mathrm{U} / \mathrm{ml}$ penicillin (all from Bio Whittaker). The parental human microvascular endothelial cell line (WT HMEC1) and HMEC1 stably expressing HA-hFcRnEGFP (HMEC1-hFcRn) ${ }^{38}$ were grown in MCDB 131 medium (Gibco) supplemented with $10 \%$ heat-inactivated FCS, $2 \mathrm{mM}$ L-glutamine and $25 \mu \mathrm{g} / \mathrm{ml}$ streptomycin, and $25 \mathrm{U} / \mathrm{ml}$ penicillin, $10 \mathrm{ng} / \mathrm{ml}$ mouse epidermal growth factor (PeproTech) and $1 \mu \mathrm{g} / \mathrm{ml}$ hydrocortisone (Sigma-Aldrich). Medium for HMEC1hFcRn was also supplemented with $5 \mu \mathrm{g} / \mathrm{ml}$ blasticidin (InvivoGen) and $100 \mu \mathrm{g} / \mathrm{ml}$ G418 (Sigma-Aldrich) to maintain stable expression of hFcRn. High five cells (Invitrogen) were grown in Express FIVE SEF medium (Invitrogen) supplemented with $18 \mathrm{mM}$ L-glutamine and $1 \%$ antibiotic-antimyotic (Invitrogen). All cell lines were negative for mycoplasma contamination (MycoAlert ${ }^{\mathrm{TM}}$ PLUS Mycoplasma detection kit, Lonza).
Production of hlgGs. Vectors encoding the WT and mutated hIgG1 HC variants with specificity for NIP and adenovirus 5 hexon have previously been reported ${ }^{44,64,65}$. The vectors were transiently transfected into HEK293E cells using Lipofectamine 2000 as described by the manufacturer (Life Technologies). Cells were co-transfected with plasmids encoding light chains with the corresponding specificity ${ }^{64,65}$. Production of an anti-NIP hIgG1-IHH variant was done using a previously described 5558L murine myeloma cell line stably transfected with pLNOH2- ${ }^{\mathrm{NIP}}$ hIgG1-IHH, which also constitutively expresses the anti-NIP mouse $\lambda$ light chain ${ }^{26}$. Growth medium was harvested and replaced every second day for 2 weeks prior to purification using a CaptureSelect ${ }^{\mathrm{TM}}$ pre-packed anti-hIgG-CH1 column (Life Technologies) as described by the manufacturer. The collected proteins were up-concentrated and buffer-changed to phosphate-buffered saline (PBS) (Sigma-Aldrich) using Amicon Ultra-15 ml 50K columns (Millipore) prior to size exclusion chromatography using a Superdex 200 increase 10/300GL column (GE 

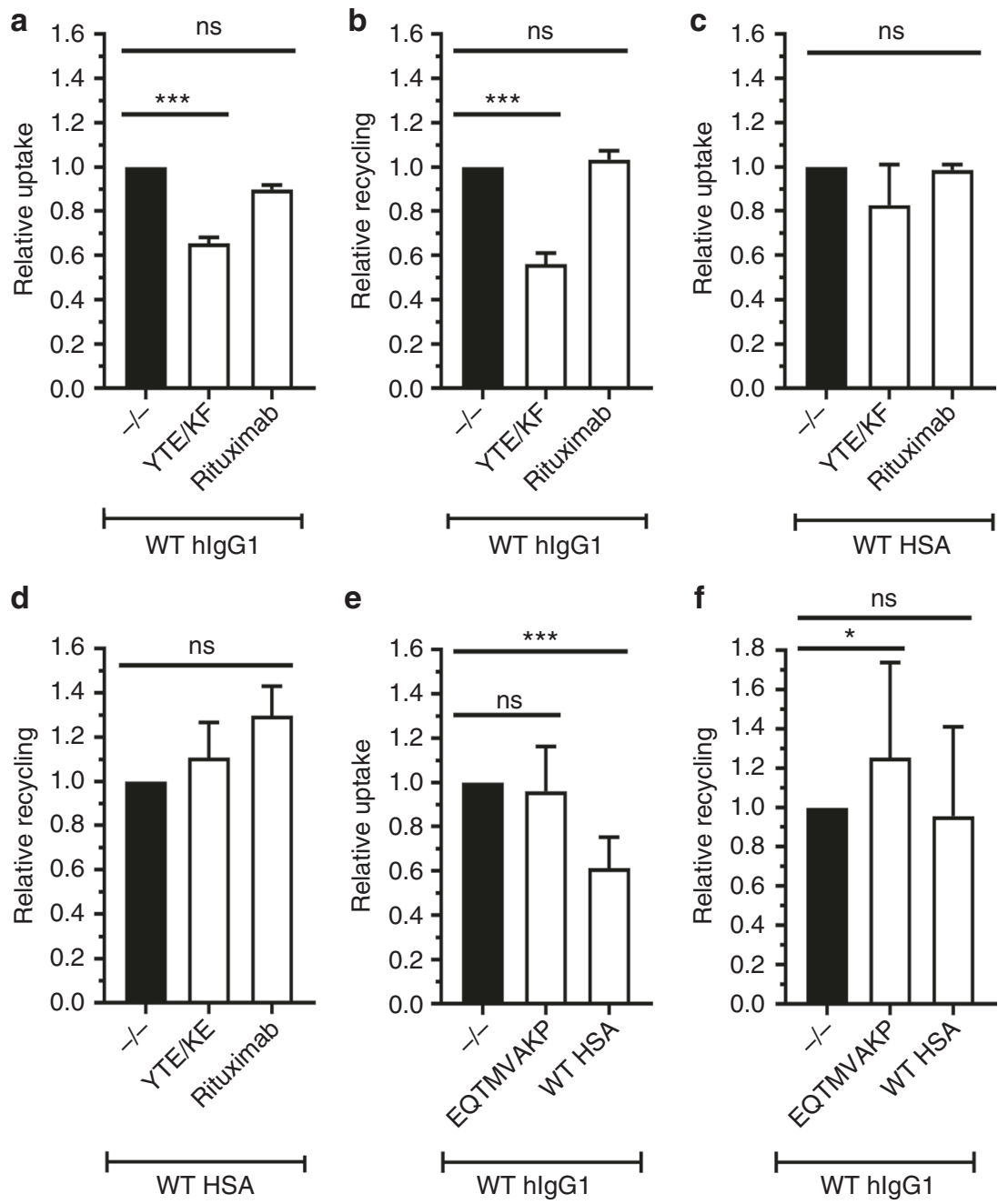

Fig. $8 \mathrm{YTE} / \mathrm{KF}$ is inhibiting rescue of IgG from degradation but not albumin. Relative $\mathbf{a}$ uptake and $\mathbf{b}$ recycling of WT hlgG1 in the absence or presence of excess amounts of YTE/KF or rituximab after $4 \mathrm{~h}$ incubation at $\mathrm{pH}$ 7.4. $\mathbf{c}$ Relative uptake and $\mathbf{d}$ recycling of WT HSA in the absence or presence of excess amounts of YTE/KF or rituximab after $4 \mathrm{~h}$ incubation at $\mathrm{pH}$ 7.4. e Relative recycling and $\mathbf{f}$ uptake of WT hlgG1 in the absence or presence of excess amounts of EQTMVAKP or WT HSA after $4 \mathrm{~h}$ incubation at $\mathrm{pH}$ 7.4. The amounts of WT hlgG1 and WT HSA were quantified using ELISA. Obtained data are shown as mean \pm s.d. of a-d three and $\mathbf{e}, \mathbf{f}$ six independent experiments performed in a-d duplicates and $\mathbf{e}, \mathbf{f}$ triplicates. ns $>0.05,{ }^{\star} p<0.05,{ }^{\star \star \star} p<$ 0.001 , by one-way ANOVA (Dunnett's multiple comparisons test)

Healthcare) and an ÄKTA FPLC instrument (GE Healthcare). The monomeric fractions were up-concentrated by Amicon Ultra- $0.5 \mathrm{ml} 100 \mathrm{~K}$ columns (Millipore).

Production of HSA variants. The cDNA fragment of full-length HSA was cloned into a pcDNA3.1 (Invitrogen), and cDNA fragments encoding DIII variants (K573P, K500A and E505Q/T527M/V547A/K573P; EQTMVAKP) were ordered (GenScrip, NJ, USA), and sub-cloned into pcDNA3.1-HSA using the restriction sites of BamHI and XhoI. In addition, cDNA sequences encoding WT HSA and K573P with a C-terminal glycine-serine linker ((GGS)4GG) were ordered (GenScript) and sub-cloned in a frame of a gene encoding EGFP in pEGFP-N1 (Clontech Laboratories) using the restriction sites of XhoI and HindIII. All HSA variants were produced in adherent HEK293E cells by transient transfection using Lipofectamine 2000 (Life Technologies). Growth medium was harvested and replaced for up to 2 weeks prior to purification using CaptureSelect HSA affinity matrix (Life technologies) packed in a $5 \mathrm{ml}$ column (Atoll). Elution from the column was done using $20 \mathrm{mM}$ Tris, $2 \mathrm{M} \mathrm{MgCl}_{2} \mathrm{pH}$ 7.4. Collected proteins were up-concentrated and buffer-changed to PBS (Sigma-Aldrich) using Amicon Ultra-

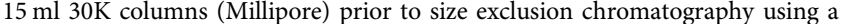
Superdex 200 increase 10/300GL column (GE Healthcare) and an ÄKTA FPLC instrument (GE Healthcare). Monomeric fractions were up-concentrated by Amicon Ultra- $0.5 \mathrm{ml} 30 \mathrm{~K}$ columns (Millipore).

Production of recombinant hFcRn. Truncated monomeric His-tagged hFcRn was produced using a Baculovirus expression system ${ }^{39,66}$. The viral stock was a kind gift from Dr. Sally Ward (University of Texas, Southwestern Medical Center, Dallas, USA). Briefly, high five cells were cultured at $1 \times 10^{6} \mathrm{cells} / \mathrm{ml}$ at $27^{\circ} \mathrm{C}$ with gentle agitation $(160 \mathrm{rpm})$, before cells $\left(500 \mathrm{ml}, 1 \times 10^{6}\right.$ cells $\left./ \mathrm{ml}\right)$ were infected with $1 \mathrm{ml}$ virus stock (Autographica californica nuclear polyhedrosis virus harbouring the pAxUW51 plasmid encoding cDNA of the three extracellular domains of $\mathrm{hFcRn}$ $\mathrm{HC}$ fused with a $\mathrm{His}_{6}$-tag and human $\beta 2$-microglobulin). After $72 \mathrm{~h}$ at $24^{\circ} \mathrm{C}$ post infection, the supernatant was harvested, and the receptor was purified using a HisTrap HP column supplied with Ni2+ ions (GE healthcare). After column equilibration with PBS containing sodium azide $(0.05 \%)$, the supernatant was adjusted to $\mathrm{pH} 7.2$ and applied on the column with a flow rate $5 \mathrm{ml} / \mathrm{min}$, then the column was washed with $200 \mathrm{ml}$ PBS followed by $50 \mathrm{ml}$ PBS containing $25 \mathrm{mM}$

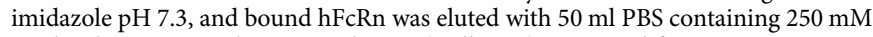
imidazole. Amicon Ultra $10 \mathrm{~K}$ columns (Millipore) were used for up-concentration and buffer-change to PBS (Sigma-Aldrich) prior to size exclusion chromatography using a HiLoad 26/600 Superdex 200 prep grade column (GE Healthcare) coupled to an ÄKTA FPLC instrument (GE Healthcare). Monomeric receptor was upconcentrated by Amicon Ultra- $0.5 \mathrm{ml} 10 \mathrm{~K}$ columns (Millipore) and stored at $4{ }^{\circ} \mathrm{C}$.

HERA. $7.5 \times 10^{5} \mathrm{HMEC} 1$ cells stably expressing HA-hFcRn-EGFP were seeded into 24-well plates per well (Costar) and cultured for 2 days in growth medium. The cells were washed twice and starved for $1 \mathrm{~h}$ in Hank's balanced salt solution (HBSS) (Life Technologies). Then, $400 \mathrm{nM}$ of either hIgG1, mIgG1 or $1600 \mathrm{nM}$ of WT HSA and MSA (Calbiochem) were diluted in $250 \mu \mathrm{l}$ HBSS (pH 7.4) and added to the cells followed by $4 \mathrm{~h}$ incubation. The medium was removed and the cells were washed four times with ice cold HBSS ( $\mathrm{pH}$ 7.4), before fresh warm HBSS ( $\mathrm{pH} 7.4)$ or growth medium without FCS and supplemented with MEM non-essential amino acids (ThermoFisher) was added. Samples were collected at $4 \mathrm{~h}$ or ON. For competition studies, 800 or $3200 \mathrm{nM}$ of DVN24, ADM12 and ADM $31^{39,40}$ were diluted 
into $200 \mu \mathrm{l}$ and added to the cells followed by $30 \mathrm{~min}$ incubation. The medium was removed and $400 \mathrm{nM}$ anti-NIP hIgG1 or $1600 \mathrm{nM}$ HSA together with DVN24, ADM12 and ADM31 were added. Five hundred nM anti-hexon hIgG1 and WT HSA were mixed with $2 \mu \mathrm{M}$ anti-NIP hIgG1-YTE/KF or $8 \mu \mathrm{M}$ rituximab (Roche) in $250 \mu \mathrm{l}$ HBSS ( $\mathrm{pH} 7.4$ ) and added to the cells. The following steps were performed as described above.

The amounts of anti-NIP or anti-hexon hIgG1 or HSA variants were quantified using ELISA as described below. HERA was also performed where the initial step was done at pH 6.0 using HBSS containing $7 \mathrm{mM}$ MES buffer (Sigma-Aldrich), $200 \mathrm{nM}$ of hIgG1, and the following steps as described above. Total protein lysates were obtained using the CelLytic M cell lysis Reagent (Sigma-Aldrich) or RIPA lysis buffer (ThermoFisher) supplied with a protease inhibitor cocktail (SigmaAldrich) or complete protease inhibitor tablets (Roche). The mixture was incubated with the cells on ice and a shaker for $10 \mathrm{~min}$ followed by centrifugation for $15 \mathrm{~min}$ at $10,000 \times g$ to remove cellular debris. Quantification of the amounts of hIgG1 or HSA variants present in the lysates was done by ELISA.

The derived values for recycling and residual amount for each of the IgG1 variants were used to calculate the HERA score. The following formula was used: $\left(R_{\mathrm{X}} / R_{\mathrm{WT}}\right) /\left(\mathrm{RA}_{\mathrm{X}} / \mathrm{RA}_{\mathrm{WT}}\right)$. The parameter $R$ (in $\left.\mathrm{ng}\right)$ is recycling at a given time while $\mathrm{RA}$ (in ng) is the residual amount. $\mathrm{X}$ is the protein of interest while WT is the parental variant used to standardize results.

Quantification of IgG. Ninety-six well plates (Costar) were coated with $1 \mu \mathrm{g} / \mathrm{ml}$ of bovine serum albumin (BSA) conjugated to NIP (BSA-NIP) (Biosearch Technologies, Inc.), recombinant AdV5 hexon (AbD Serotec) or polyclonal anti-human or mouse $\mathrm{Fc}$-specific antibody from goat (locally produced) diluted $(0.2 \mu \mathrm{g} / \mathrm{ml})$ in PBS. After incubation ON at $4{ }^{\circ} \mathrm{C}$, plates were blocked with PBS containing $4 \%$ skimmed milk (S) (Sigma-Aldrich) for $1 \mathrm{~h}$ at room temperature (RT) and washed four times with PBS containing $0.05 \%$ Tween 20 (T) (Sigma-Aldrich). Serial dilutions of IgGs $(250.0-0.1 \mathrm{ng} / \mathrm{ml})$ were added in parallel with samples collected from HERA and incubated for $2 \mathrm{~h}$ at RT. The plates were washed four times as above, before alkaline phosphatase-conjugated polyclonal anti-mIgG or hIgG Fc$\mathrm{Ab}$ from goat (\#A2429, \#A9544, Sigma-Aldrich), diluted (1:4000) in 4\% PBS/S/T, was added for $1.5 \mathrm{~h}$ at RT. The plates were washed as above before $100 \mu \mathrm{l}$ of the $p$ nitropenylphospate substrate (Sigma-Aldrich) diluted to $10 \mu \mathrm{g} / \mathrm{ml}$ in diethanolamine buffer was added. The absorbance was measured at $405 \mathrm{~nm}$ using a Sunrise spectrophotometer (TECAN).

Quantification of albumin. Ninety-six-well ELISA plates (Costar) were coated with $1.0 \mu \mathrm{g} / \mathrm{ml}$ of polyclonal goat anti-HSA (\#A1151, Sigma-Aldrich) or polyclonal anti-MSA (\#ab19194, Abcam) antibodies, $1.0 \mu \mathrm{g} / \mathrm{ml}$ diluted in PBS, and incubated ON at $4{ }^{\circ} \mathrm{C}$. Plates were blocked with $\mathrm{PBS} / \mathrm{S}$ ON at $4{ }^{\circ} \mathrm{C}$ and washed four times with $\mathrm{PBS} / \mathrm{T}$ before serial dilutions of MSA or HSA $(250.0-0.1 \mathrm{ng} / \mathrm{ml})$ in PBS/S/T were applied in parallel with samples from HERA followed by $2 \mathrm{~h}$ incubation at RT. Bound MSA and HSA were detected using horseradish peroxidase-conjugated polyclonal anti-MSA antibody from goat (\#ab19195; Abcam, 1:4000) or alkaline phosphatase-conjugated polyclonal anti-HSA antibody from goat (\#A80229AP; Bethyl Laboratories, Inc., 1:5000). ELISAs were developed by adding $100 \mu \mathrm{l}$ of 3,3 ',5,5'-tetramethylbenzinide solution (Calbiochem) and the reaction was stopped by adding $100 \mu \mathrm{l}$ of $1 \mathrm{M} \mathrm{HCl}$ for MSA, while for HSA $100 \mu \mathrm{l}$ of the $p$-nitropenylphospate substrate (Sigma-Aldrich) diluted to $10 \mu \mathrm{g} / \mathrm{ml}$ in diethanolamine buffer was added. The absorbance was measured at 450 or $405 \mathrm{~nm}$ using a Sunrise spectrophotometer (TECAN).

Quantification of hFcRn. Membrane-bound proteins were extracted from WT HMEC1 and HMEC1-hFcRn cell lines using a Native Membrane Extraction kit as described by the manufacturer (Calbiochem). The final fractions were stored at $-80^{\circ} \mathrm{C}$ until analysed in ELISA. Ninety-six-well plates (Costar) were coated with 8 $\mu \mathrm{g} / \mathrm{ml}$ of hIgG1-YTE $/ \mathrm{KF}$ and incubated overnight at $4^{\circ} \mathrm{C}$ before plates were blocked with PBS/S for $1 \mathrm{~h}$ at RT and then washed four times with PBS/T at pH 5.5 ( $100 \mathrm{mM}$ phosphate buffer, $0.15 \mathrm{M} \mathrm{NaCl}, 0.05 \%$ Tween 20 ). Serial dilutions of hFcRn $(500.0-0.2 \mathrm{ng} / \mathrm{ml})$ in PBS/S/T pH 5.5 were added in parallel with $2 \mu \mathrm{g}$ of extracted membrane proteins followed by incubation for $2 \mathrm{~h}$ at RT. The plates were washed four times as above, before $1 \mu \mathrm{g} / \mathrm{ml}$ of biotinylated ADM31 was added and incubated for $1.5 \mathrm{~h}$ at RT followed by washing and detection using alkaline phosphatase-conjugated streptavidin (GE healthcare) diluted (1:3000) in PBS/T pH 5.5. The plates were washed as above before $100 \mu \mathrm{l} p$-nitropenylphosphate $(10 \mu \mathrm{g} /$ $\mathrm{ml}$ ) diluted in diethanolamine buffer was added. The absorbance was measured at $405 \mathrm{~nm}$ using a Sunrise spectrophotometer (TECAN).

SDS-PAGE and western blotting. Extracted membrane protein fractions from HMEC1-hFcRn cells treated with a mixture of control siRNA or siRNA targeting the hFcRn HC were separated on a non-reducing $12 \%$ Bis-Tris plus gel (Invitrogen) and transferred onto a polyvinylidene fluoride membrane (Millipore) in Tris/ glycine buffer ( $25 \mathrm{mM}$ Tris, $192 \mathrm{mM}$ glycine, and $20 \%$ methanol, $\mathrm{pH} 8.3$ ) at $25 \mathrm{~V}$ for $30 \mathrm{~min}$ using a semi-dry blotting apparatus (Bio-Rad). The membrane was blocked with PBS/S/T before added horseradish peroxidase-conjugated anti-HAtag polyclonal Ab produced in goat (\#ab1265, Abcam, 1:5000) to detect HA-tagged hFcRn. The membrane was washed four times with PBS/T and developed with a
SuperSignal West Femto substrate (Pierce) and image acquired by the G:BOX instrument (Syngene).

FCRn-lgG binding ELISA. Ninety-six-well plates (Costar) were coated with $2 \mu \mathrm{g} / \mathrm{ml}$ of BSA-NIP (Biosearch Technologies, Inc.) diluted in PBS and incubated ON at $4{ }^{\circ}$ C. Plates were blocked with PBS/S for $1 \mathrm{~h}$ at RT and then washed four times with PBS/T. Serial dilutions of WT IgG1 and Fc-engineered variants $(10,000-1.5 \mathrm{ng} / \mathrm{ml})$ in PBS/S/T were added and incubated for $1 \mathrm{~h}$ at RT. The plates were washed four times as above, before site-specific biotinylated $\mathrm{mFcRn}$ and $\mathrm{hFcRn}(2.5 \mu \mathrm{g} / \mathrm{ml})$ (Immunitrack) diluted in PBS/S/T pH $5.5(100 \mathrm{mM}$ phosphate buffer, $0.15 \mathrm{M} \mathrm{NaCl}$, $4 \%$ skimmed milk, $0.05 \%$ Tween 20 ) or $\mathrm{PBS} / \mathrm{S} / \mathrm{T} \mathrm{pH} 7.4$ was added followed by incubation for $1 \mathrm{~h}$ at RT. After washing four times with either $\mathrm{pH} 5.5$ or $\mathrm{pH} 7.4$ PBS/T, alkaline phosphatase-conjugated streptavidin (GE Healthcare) diluted (1:3000) in $\mathrm{pH} 5.5$ or $\mathrm{pH} 7.4 \mathrm{PBS} / \mathrm{S} / \mathrm{T}$ was added for $1 \mathrm{~h}$ at RT. The plates were washed as above before $100 \mu \mathrm{l}$ of the $p$-nitropenylphospate substrate (SigmaAldrich) diluted $(10 \mu \mathrm{g} / \mathrm{ml})$ in diethanolamine buffer was added. The absorbance was measured at $405 \mathrm{~nm}$ using a Sunrise spectrophotometer (TECAN).

FcRn-HSA binding ELISA. Ninety-six-well ELISA plates (Costar) were coated with $8 \mu \mathrm{g} / \mathrm{ml}$ of hIgG1-YTE/KF diluted in PBS, and incubated ON at $4{ }^{\circ} \mathrm{C}$. Plates were blocked with $\mathrm{PBS} / \mathrm{S}$ for $1 \mathrm{~h}$ at RT, and then washed four times with PBS/T. Histagged $\mathrm{hFcRn}(10 \mu \mathrm{g} / \mathrm{ml})$ in $\mathrm{pH} 5.5$ or $\mathrm{pH} 7.4 \mathrm{PBS} / \mathrm{S} / \mathrm{T}$ was added and incubated for $1 \mathrm{~h}$ at RT. The plates were washed four times with either $\mathrm{pH} 5.5$ or $\mathrm{pH} 7.4 \mathrm{PBS} / \mathrm{T}$, before serial dilutions $(15,000-7.3 \mathrm{ng} / \mathrm{ml})$ of WT HSA or HSA-EQTMVAKP in $\mathrm{pH}$ 5.5 or $\mathrm{pH} 7.4 \mathrm{PBS} / \mathrm{S} / \mathrm{T}$ were added, and incubated for $1 \mathrm{~h}$ at $\mathrm{RT}$. The plates were washed four times as above, before alkaline phosphatase-conjugated polyclonal anti-HSA antibody from goat (\#A80229AP; Bethyl Laboratories, Inc., 1:5000), diluted (1:3000) in $\mathrm{pH} 5.5$ or $\mathrm{pH} 7.4 \mathrm{PBS} / \mathrm{S} / \mathrm{T}$ was added for $1 \mathrm{~h}$ at RT. The plates were washed four times and developed as above.

MicroScale Thermophoresis assay. A Monolith NT.115 instrument (Nano Temper Technologies GmbH, Munich, Germany) ${ }^{67}$ was used where anti-NIP hIgG1 variants labelled with NT-647-HNS fluorescent dye (Nano Temper Technologies) or C-terminally EGFP-fused HSA variants were used. Titrated amounts of hFcRn $(60,000-0.3 \mathrm{nM})$ were incubated with $20 \mathrm{nM}$ of each of the labelled hIgG1 variants or $100 \mathrm{nM}$ HSA-EGFP at RT for $10 \mathrm{~min}$ in PBS pH 7.4 or $100 \mathrm{mM}$ phosphate buffer $\left(6 \mathrm{mM} \mathrm{Na}_{2} \mathrm{HPO}_{4} \times 2 \mathrm{H}_{2} \mathrm{O}, 94 \mathrm{mM} \mathrm{NaH}_{2} \mathrm{PO}_{4} \times \mathrm{H}_{2} \mathrm{O}, 150 \mathrm{mM} \mathrm{NaCl}\right)$ $\mathrm{pH} 5.5$, both buffers supplemented with $0.01 \% \mathrm{~T}$. Samples were loaded onto premium-coated capillaries (Nano Temper Technologies). Measurements were performed at $25^{\circ} \mathrm{C}$ using $40 \% \mathrm{LED}$ and $40 \%$ MicroScale Thermophoresis power for hIgG1 variants, and $80 \%$ LED and $60 \%$ power for HSA-EGFP variants. All experiments were repeated three times for each measurement, and data analyses were done using Nano Temper analysis software.

Analytical hFcRn affinity chromatography. Analytical hFcRn affinity chromatography was performed using an ÄKTA Avant 25 instrument (GE Healthcare), essentially as previously described ${ }^{58,68}$. Briefly, $50 \mu \mathrm{l}$ WT hIgG1 and Fc-engineered variants $(1 \mathrm{mg} / \mathrm{ml})$ were injected and eluted by a linear $\mathrm{pH}$ gradient from $\mathrm{pH} 6.0$ to 8.8 within $110 \mathrm{~min}$ using $20 \mathrm{mM}$ MES sodium salt, $140 \mathrm{mM} \mathrm{NaCl} \mathrm{pH} 5.5$ and 20 $\mathrm{mM}$ Tris/ $\mathrm{HCl}, 140 \mathrm{NaCl}, \mathrm{pH} 8.8$ as eluents. To determine the elution $\mathrm{pH}$ at particular retention times, the $\mathrm{pH}$ was monitored by a $\mathrm{pH}$ detector (GE Healthcare). HSA variants were analysed using $2 \mathrm{mg} / \mathrm{ml}$ followed by a $\mathrm{pH}$ elution gradient from $\mathrm{pH} 5.5$ to 8.8 within $110 \mathrm{~min}$ using the same buffers as above.

siRNA knockdown of FcRn expression. HMEC1-hFcRn cells were transfected with a mixture of three control siRNAs or hFcRn HC-specific siRNAs (sc-37007, sc-45632; Santa Cruz Biotechnology Inc). The sequences of hFcRn HC-specific siRNAs are shown in Supplementary Table 2. For each transfection, a siRNA mixture was diluted in siRNA transfection medium and transfection reagent, essentially as described by the manufacturer (Santa Cruz Biotechnology Inc). Cells were incubated for $6 \mathrm{~h}$ at $37^{\circ} \mathrm{C}$ in a $\mathrm{CO}_{2}$ incubator followed by adding MCDB 131 medium with $20 \%$ FCS and $200 \mathrm{U} / \mathrm{ml}$ PS. Cells were then incubated for additional $24 \mathrm{~h}$ before medium was replaced with MCDB 131 medium.

Confocal laser scanning microscopy. HMEC1-hFcRn-EGFP cells were seeded in eight-well NuncTM Lab-Tek ${ }^{\mathrm{TM}}$ chambered Coverglass imaging dishes (ThermoFisher Scientific), and grown to $50-70 \%$ confluency. WT and IHH hIgG1 variants were conjugated with Alexa-647 following the manufacturer's procedure (Life Technologies). Cells were washed three times with HBSS pH 6.0 and Alexa-647 conjugated antibodies, diluted in HBSS pH 6.0 to the final concentration of 400 $\mathrm{nM}$, were added to the cells and incubated for $4 \mathrm{~h}$ before pictures were taken. The cells were then washed three times with HBSS $\mathrm{pH}$ 7.4, and incubated in HBSS pH 7.4 for $4 \mathrm{~h}$ before pictures were taken. Lysotracker DND-99 (Life Technologies) was added to the cells $30 \mathrm{~min}$ before pictures were taken. Confocal images were acquired on an Olympus FluoView 1000 inverted microscope equipped with a PlanApo 60/1.42 oil objective (Olympus). Constant temperature was set to $37^{\circ} \mathrm{C}$ and $\mathrm{CO}_{2}$ to $5 \%$ by an incubator enclosing the microscope stage. Image acquisition was done by sequential line scanning to eliminate bleed-through. Images were processed and prepared with ImageJ (NIH), Adobe Photoshop and Illustrator 
(Adobe system Inc). Co-localization was quantified using Imaris spot colocalization software (Bitplane) where the endosome size was set to $1 \mu \mathrm{m}$. Data from two independent experiments with 15-20 cells analysed were used for colocalization analysis.

In vivo studies. Hemizygous $\mathrm{Tg} 32$ mice (B6.Cg-Fcgrt ${ }^{\mathrm{tm} 1 \mathrm{Dcr}} \mathrm{Tg}$ (FCGRT)32Dcr/ DcrJ; The Jackson Laboratory) that are transgenic for the hFcRn gene and WT mice (BALB/c; Taconic) were used to determine the half-life of the hIgG1 antibodies, except for YTE/KF that was evaluated in homozygous Tg32 mice. Male mice, age 7-9 weeks, weighing between 17 and $27 \mathrm{~g}$ ( 5 mice per group), received 5 $\mathrm{mg} / \mathrm{kg}$ of hIgG1 variants diluted in PBS by intravenous injections. Blood samples $(25 \mu \mathrm{l})$ were drawn from the retro-orbital sinus of the Tg32 mice at days $1,3,5,7$, $10,12,16,19,23,30$ and 37 after injection. WT mice had blood drawn from the saphenous vein on days $0,1,2,4,6,8,10$ and 12 after injection. The blood samples were immediately mixed with $1 \mu \mathrm{l} 1 \% \mathrm{~K} 3$-EDTA to prevent coagulation and then centrifuged at $17,000 \times g$ for $5 \mathrm{~min}$ at $4{ }^{\circ} \mathrm{C}$. Plasma was isolated and diluted 1:10 in $50 \%$ glycerol/PBS solution and then stored at $-20^{\circ} \mathrm{C}$ until analysis by ELISA as described above. Plasma samples were diluted 1:400 in PBS/S/T and $100 \mu \mathrm{l}$ was added per well in the ELISA plate. The Tg32 mice studies were carried out at The Jackson Laboratory (JAX Services, Bar Harbor, ME), while the WT mouse study was done at the Department of Immunology, Oslo University Hospital, Rikshospitalet. The experiments and procedures used were all approved by the Animal Care and Use Committee at The Jackson Laboratory (Tg32 study) and the Norwegian Animal Research Authority (BALB/c study), and were performed in accordance with the approved guidelines and regulations.

Half-life calculation. The plasma concentration of the hIgG1 antibodies was presented as percentage remaining in the circulation at different time points after injection compared to the concentration on day 1 (100\%). Nonlinear regression analysis was performed to fit a straight line through the data using Prism 7 . The $\beta$ phase half-life was calculated using the formula: $t_{1 / 2}=\log 0.5 /\left(\log A_{\mathrm{e}} / A_{0}\right) \times t$, where $t_{1 / 2}$ is the half-life of the hIgG1 evaluated, $A_{\mathrm{e}}$ is the amount of hIgG1 remaining, $A_{0}$ is the amount of hIgG1 on day 1 and $t$ is the elapsed time.

Statistical analysis. Figures were generated and statistical analyses (ANOVA with Tukey's multiple comparisons test or Dunnett's multiple comparison test, with a $95 \%$ confidence interval and $p<0.05$ was considered a statistically significant difference) were performed using GraphPad Prism 7 for Windows (Version 7.02; GraphPad Software Inc.) and Microsoft Excel 2010 (Microsoft).

Data availability. The data that support the findings of this study are available from the corresponding author upon reasonable request.

Received: 30 June 2017 Accepted: 17 January 2018

Published online: 12 February 2018

\section{References}

1. Köhler, G. \& Milstein, C. Continuous cultures of fused cells secreting antibody of predefined specificity. Nature 256, 495-497 (1975).

2. Chan, A. C. \& Carter, P. J. Therapeutic antibodies for autoimmunity and inflammation. Nat. Rev. Immunol. 10, 301-316 (2010).

3. Brekke, O. H. \& Sandlie, I. Therapeutic antibodies for human diseases at the dawn of the twenty-first century. Nat. Rev. Drug Discov. 2, 52-62 (2003).

4. Nelson, A. L., Dhimolea, E. \& Reichert, J. M. Development trends for human monoclonal antibody therapeutics. Nat. Rev. Drug Discov. 9, 767-774 (2010).

5. Spiegelberg, H. L. \& Fishkin, B. G. The catabolism of human G immunoglobulins of different heavy chain subclasses. 3 . The catabolism of heavy chain disease proteins and of Fc fragments of myeloma proteins. Clin. Exp. Immunol. 10, 599-607 (1972).

6. Bern, M., Sand, K. M., Nilsen, J., Sandlie, I. \& Andersen, J. T. The role of albumin receptors in regulation of albumin homeostasis: Implications for drug delivery. J. Control Release 211, 144-162 (2015).

7. Sand, K. M. et al. Unraveling the interaction between FcRn and Albumin: opportunities for design of albumin-based therapeutics. Front. Immunol. 5, 682 (2014).

8. Burmeister, W. P., Huber, A. H. \& Bjorkman, P. J. Crystal structure of the complex of rat neonatal Fc receptor with Fc. Nature 372, 379-383 (1994).

9. West, A. P. \& Bjorkman, P. J. Crystal structure and immunoglobulin G binding properties of the human major histocompatibility complex-related Fc receptor(,). Biochemistry 39, 9698-9708 (2000).

10. Simister, N. E. \& Mostov, K. E. An Fc receptor structurally related to MHC class I antigens. Nature 337, 184-187 (1989).

11. Stapleton, N. M. et al. Competition for FcRn-mediated transport gives rise to short half-life of human IgG3 and offers therapeutic potential. Nat. Commun. 2, 599 (2011).
12. Chaudhury, C., Brooks, C. L., Carter, D. C., Robinson, J. M. \& Anderson, C. L. Albumin binding to FcRn: distinct from the FcRn-IgG interaction. Biochemistry 45, 4983-4990 (2006).

13. Kim, J. K. et al. Mapping the site on human IgG for binding of the MHC class I-related receptor, FcRn. Eur. J. Immunol. 29, 2819-2825 (1999).

14. Andersen, J. T. et al. Structure-based mutagenesis reveals the albumin-binding site of the neonatal Fc receptor. Nat. Commun. 3, 610 (2012).

15. Sand, K. M. et al. Interaction with both domain I and III of albumin is required for optimal $\mathrm{pH}$-dependent binding to the neonatal $\mathrm{Fc}$ receptor (FcRn). J. Biol. Chem. 289, 34583-34594 (2014).

16. Oganesyan, V. et al. Structural insights into neonatal Fc receptor-based recycling mechanisms. J. Biol. Chem. 289, 7812-7824 (2014).

17. Ober, R. J., Martinez, C., Vaccaro, C., Zhou, J. \& Ward, E. S. Visualizing the site and dynamics of IgG salvage by the MHC class I-related receptor, FcRn. J. Immunol. 172, 2021-2029 (2004)

18. Ober, R. J., Martinez, C., Lai, X., Zhou, J. \& Ward, E. S. Exocytosis of IgG as mediated by the receptor, FcRn: an analysis at the single-molecule level. Proc. Natl. Acad. Sci. USA 101, 11076-11081 (2004).

19. Prabhat, P. et al. Elucidation of intracellular recycling pathways leading to exocytosis of the $\mathrm{Fc}$ receptor, FcRn, by using multifocal plane microscopy. Proc. Natl. Acad. Sci. USA 104, 5889-5894 (2007).

20. Ward, E. S. et al. From sorting endosomes to exocytosis: association of Rab4 and Rab11 GTPases with the Fc receptor, FcRn, during recycling. Mol. Biol. Cell. 16, 2028-2038 (2005).

21. Chaudhury, C. et al. The major histocompatibility complex-related Fc receptor for IgG $(\mathrm{FcRn})$ binds albumin and prolongs its lifespan. J. Exp. Med. 197, 315-322 (2003).

22. Andersen, J. T., Qian, J. Dee \& Sandlie, I. The conserved histidine 166 residue of the human neonatal $\mathrm{Fc}$ receptor heavy chain is critical for the $\mathrm{pH}$ dependent binding to albumin. Eur. J. Immunol. 36, 3044-3051 (2006).

23. Schmidt, E. G. W. G. et al. Direct demonstration of a neonatal Fc receptor ( FcRn)-driven endosomal sorting pathway for cellular recycling of albumin. J. Biol. Chem. 292, 13312-13322 (2017).

24. Montoyo, H. P. P. et al. Conditional deletion of the MHC class I-related receptor FcRn reveals the sites of IgG homeostasis in mice. Proc. Natl. Acad. Sci. USA 106, 2788-2793 (2009).

25. Akilesh, S., Christianson, G. J., Roopenian, D. C. \& Shaw, A. S. Neonatal FcR expression in bone marrow-derived cells functions to protect serum IgG from catabolism. J. Immunol. 179, 4580-4588 (2007).

26. Qiao, S.-W. W. et al. Dependence of antibody-mediated presentation of antigen on FcRn. Proc. Natl. Acad. Sci. USA 105, 9337-9342 (2008).

27. Pyzik, M. et al. Hepatic FcRn regulates albumin homeostasis and susceptibility to liver injury. Proc. Natl. Acad. Sci. USA 114, E2862-E2871 (2017).

28. Vaccaro, C., Bawdon, R., Wanjie, S., Ober, R. J. \& Ward, E. S. Divergent activities of an engineered antibody in murine and human systems have implications for therapeutic antibodies. Proc. Natl. Acad. Sci. USA 103, 18709-18714 (2006)

29. Andersen, J. T., Daba, M. B., Berntzen, G., Michaelsen, T. E. \& Sandlie, I. Cross-species binding analyses of mouse and human neonatal Fc receptor show dramatic differences in immunoglobulin $\mathrm{G}$ and albumin binding. J. Biol. Chem. 285, 4826-4836 (2010)

30. Petkova, S. B. et al. Enhanced half-life of genetically engineered human IgG1 antibodies in a humanized FcRn mouse model: potential application in humorally mediated autoimmune disease. Int. Immunol. 18, 1759-1769 (2006).

31. Ober, R. J., Radu, C. G., Ghetie, V. \& Ward, E. S. Differences in promiscuity for antibody-FcRn interactions across species: implications for therapeutic antibodies. Int. Immunol. 13, 1551-1559 (2001).

32. Frödin, J.-E., Lefvert, A.-K. \& Mellstedt, H. Pharmacokinetics of the mouse monoclonal antibody $17-1 \mathrm{~A}$ in cancer patients receiving various treatment schedules. Cancer Res. 50, 4866-4871 (1990).

33. Ghetie, V. et al. Increasing the serum persistence of an IgG fragment by random mutagenesis. Nat. Biotechnol. 15, 637-640 (1997).

34. Ghetie, V. et al. Abnormally short serum half-lives of IgG in beta 2 microglobulin-deficient mice. Eur. J. Immunol. 26, 690-696 (1996).

35. Andersen, J. T. et al. Extending serum half-life of albumin by engineering neonatal Fc receptor (FcRn) binding. J. Biol. Chem. 289, 13492-13502 (2014).

36. Roopenian, D. C. et al. Albumin-deficient mouse models for studying metabolism of human albumin and pharmacokinetics of albumin-based drugs. MAbs 7, 344-351 (2015).

37. Stein, C. et al. Clinical chemistry of human FcRn transgenic mice. Mamm Genome 23, 259-269 (2012).

38. Weflen, A. W. et al. Multivalent immune complexes divert FcRn to lysosomes by exclusion from recycling sorting tubules. Mol. Biol. Cell 24, 2398-2405 (2013).

39. Sand, K. M. et al. Dissection of the neonatal $F_{c}$ receptor ( $\left.F c R n\right)$-albumin interface using mutagenesis and anti-FcRn albumin-blocking antibodies. $J$. Biol. Chem. 289, 17228-17239 (2014).

40. Christianson, G. J. et al. Monoclonal antibodies directed against human FcRn and their applications. MAbs 4, 208-216 (2012). 
41. Vaccaro, C., Zhou, J., Ober, R. J. \& Ward, E. S. Engineering the Fc region of immunoglobulin G to modulate in vivo antibody levels. Nat. Biotechnol. 23, 1283-1288 (2005).

42. Zalevsky, J. et al. Enhanced antibody half-life improves in vivo activity. Nat. Biotechnol. 28, 157-159 (2010).

43. Dall'Acqua, W. F., Kiener, P. A. \& Wu, H. Properties of human IgG1s engineered for enhanced binding to the neonatal Fc receptor (FcRn). J. Biol. Chem. 281, 23514-23524 (2006).

44. Grevys, A. et al. Fc engineering of human IgG1 for altered binding to the neonatal Fc receptor affects Fc effector functions. J. Immunol. 194, 5497-5508 (2015).

45. Ward, E. S., Zhou, J., Ghetie, V. \& Ober, R. J. Evidence to support the cellular mechanism involved in serum IgG homeostasis in humans. Int. Immunol. 15, 187-195 (2003).

46. Gan, Z., Ram, S., Vaccaro, C., Ober, R. J. \& Ward, E. S. Analyses of the recycling receptor, $\mathrm{FcRn}$, in live cells reveal novel pathways for lysosomal delivery. Traffic 10, 600-614 (2009).

47. Robbie, G. J. et al. A novel investigational Fc-modified humanized monoclonal antibody, motavizumab-YTE, has an extended half-life in healthy adults. Antimicrob. Agents Chemother. 57, 6147-6153 (2013).

48. Patel, D. A. et al. Neonatal Fc receptor blockade by Fc engineering ameliorates arthritis in a murine model. J. Immunol. 187, 1015-1022 (2011).

49. Anderson, C. L. There's been a flaw in our thinking. Front. Immunol. 5, 540 (2014).

50. Ward, E. S. \& Ober, R. J. Commentary: 'There's been a flaw in our thinking'. Front. Immunol. 6, 351 (2015).

51. Goebl, N. A. et al. Neonatal Fc receptor mediates internalization of Fc in transfected human endothelial cells. Mol. Biol. Cell 19, 5490-5505 (2008)

52. Borrok, M. J. et al. $\mathrm{pH}$-dependent binding engineering reveals an $\mathrm{FcRn}$ affinity threshold that governs IgG recycling. J. Biol. Chem. 290, 4282-4290 (2015).

53. Ward, E. S., Devanaboyina, S. C. \& Ober, R. J. Targeting FcRn for the modulation of antibody dynamics. Mol. Immunol. 67, 131-141 (2015).

54. Igawa, T. et al. Antibody recycling by engineered $\mathrm{pH}$-dependent antigen binding improves the duration of antigen neutralization. Nat. Biotechnol. 28, 1203-1207 (2010).

55. Igawa, T. et al. Reduced elimination of IgG antibodies by engineering the variable region. Protein Eng. Des. Sel. 23, 385-392 (2010).

56. Li, B. et al. Framework selection can influence pharmacokinetics of a humanized therapeutic antibody through differences in molecule charge. MAbs 6, 1255-1264 (2014).

57. Jensen, P. F. et al. Investigating the interaction between the neonatal Fc receptor and monoclonal antibody variants by hydrogen/deuterium exchange mass spectrometry. Mol. Cell. Proteom. 14, 148-161 (2015).

58. Schoch, A. et al. Charge-mediated influence of the antibody variable domain on FcRn-dependent pharmacokinetics. Proc. Natl. Acad. Sci. USA 112, 5997-6002 (2015).

59. Piche-Nicholas, N. M. et al. Changes in complementarity-determining regions significantly alter IgG binding to the neonatal Fc receptor (FcRn) and pharmacokinetics. MAbs 1-14 (2017). https://doi.org/10.1080/ 19420862.2017.1389355

60. Frese, K., Eisenmann, M., Ostendorp, R., Brocks, B. \& Pabst, S. An automated immunoassay for early specificity profiling of antibodies. MAbs 5, 279-287 (2013).

61. Hötzel, I. et al. A strategy for risk mitigation of antibodies with fast clearance. MAbs 4, 753-760 (2012).

62. Kelly, R. L. et al. High throughput cross-interaction measures for human IgG1 antibodies correlate with clearance rates in mice. MAbs 7, 770-777 (2015).

63. Kelly, R. L. et al. Chaperone proteins as single component reagents to assess antibody nonspecificity. MAbs 9, 1036-1040 (2017).

64. Norderhaug, L., Olafsen, T., Michaelsen, T. E. \& Sandlie, I. Versatile vectors for transient and stable expression of recombinant antibody molecules in mammalian cells. J. Immunol. Methods 204, 77-87 (1997).

65. Foss, S. et al. TRIM 21 immune signaling is more sensitive to antibody affinity than its neutralization activity. J. Immunol. 196, 3452-3459 (2016).
66. Firan, M. et al. The MHC class I-related receptor, FcRn, plays an essential role in the maternofetal transfer of gamma-globulin in humans. Int. Immunol. 13, 993-1002 (2001).

67. Wienken, C. J., Baaske, P., Rothbauer, U., Braun, D. \& Duhr, S. Proteinbinding assays in biological liquids using microscale thermophoresis. Nat. Commun. 1, 100 (2010).

68. Schlothauer, T. et al. Analytical FcRn affinity chromatography for functional characterization of monoclonal antibodies. MAbs 5, 576-586 (2013).

69. Saphire, E. O. et al. Crystal structure of a neutralizing human IGG against HIV-1: a template for vaccine design. Science 293, 1155-1159 (2001).

70. Sugio, S., Kashima, A., Mochizuki, S., Noda, M. \& Kobayashi, K. Crystal structure of human serum albumin at 2.5 A resolution. Protein Eng. 12, 439-446 (1999)

\section{Acknowledgements}

We are grateful to Sathiaruby Sivaganesh for excellent technical assistance. This work was supported in part by the Research Council of Norway through its Centre of Excellence funding scheme (Project 179573). J.T.A. and J.N. were supported by the Research Council of Norway (Grants 230526/F20 and 179573/V40). M.B.M. was supported by the Research Council of Norway (Grant 179573/V40). M.B. was supported by the Research Council of Norway through its program for Global Health and Vaccination Research (Grant 143822). S.F. and A.G. were supported by the University of Oslo. We thank Dr. Wayne I. Lencer (Boston Children's Hospital, Harvard Medical School and Harvard Digestive Diseases Center, USA) for the WT HMEC1 and the HMEC1 cell line stably expressing HA-hFcRn-EGFP and Dr. Finn Eirik Johansen (University of Oslo, Norway) for the J558L cell line stably expressing NIP-specific hIgG1-IHH. We acknowledge the use of the NorMIC Oslo imaging platform at the Department of Biosciences, University of Oslo.

\section{Author contributions}

A.G., M.B.D., I.S. and J.T.A. designed research; A.G., K.M.K.S, J.N., G.J.C, M.B., M.B.D., S.F., M.B.M. and I.Ø. performed research; A.G., K.M.K.S, J.N., M.B.D., S.F., T.S., T.E.M., R.S.B., D.C.R. and I.Ø. analysed data; A.G., I.S. and J.T.A. wrote the paper.

\section{Additional information}

Supplementary Information accompanies this paper at https://doi.org/10.1038/s41467018-03061-x.

Competing interests: The authors declare no conflicting financial interests.

Reprints and permission information is available online at http://npg.nature.com/ reprintsandpermissions/

Publisher's note: Springer Nature remains neutral with regard to jurisdictional claims in published maps and institutional affiliations.

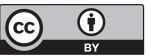

Open Access This article is licensed under a Creative Commons Attribution 4.0 International License, which permits use, sharing, adaptation, distribution and reproduction in any medium or format, as long as you give appropriate credit to the original author(s) and the source, provide a link to the Creative Commons license, and indicate if changes were made. The images or other third party material in this article are included in the article's Creative Commons license, unless indicated otherwise in a credit line to the material. If material is not included in the article's Creative Commons license and your intended use is not permitted by statutory regulation or exceeds the permitted use, you will need to obtain permission directly from the copyright holder. To view a copy of this license, visit http://creativecommons.org/ licenses/by/4.0/.

(c) The Author(s) 2018 